\title{
LOS ASENTAMIENTOS RURALES DE ÉPOCA ROMANA EN EL CONTEXTO DEL BAIXO MIÑO: EL YACIMIENTO DE CURRÁS, TOMIÑO
}

\author{
Silvia González Soutelo \\ Universidad Autónoma de Madrid / MIAS y Universidad de Vigo \\ ORCID iD: https://orcid.org/0000-0001-8737-8740 \\ FERMÍN E. PÉREZ LOSADA \\ Universidad de Vigo \\ ORCID iD: https://orcid.org/0000-0001-8554-9542 \\ Patricia Valle Abad \\ Universidad de Vigo \\ ORCID iD: https://orcid.org/0000-0002-3080-614X \\ Martiño X. VÁZquez Mato \\ Universidad de Vigo \\ ORCID iD: https://orcid.org/0000-0002-3525-0988
}

\begin{abstract}
* Nuestro más sincero agradecimiento a la Comunidad de Montes de Currás y a la Asociación de Vecinos "Os Medos" de Currás por su interés, por su dedicación y por su ilusión; al Museo Diocesano de Tui, por las facilidades prestadas; a los alumnos en prácticas que participaron en las actividades vinculadas al yacimiento; así como al concello de Tomiño por su apoyo incondicional para recuperar su patrimonio.

Agradecer, igualmente, los comentarios y sugerencias realizadas por los revisores de este artículo que, sin duda, han contribuido a la mejora substancial del mismo.
\end{abstract}

Copyright: (C) 2019 CSIC. La edición electrónica de esta revista se distribuye bajo los términos de una licencia de uso y distribución Creative Commons Reconocimiento 4.0 Internacional (CC BY 4.0).

Cómo citar/Citation: Silvia González Soutelo, Fermín E. Pérez Losada, Patricia Valle ABAD y Martiño X. VÁZqUEZ Mato, "Los asentamientos rurales de época romana en el contexto del Baixo Miño: el yacimiento de Currás, Tomiño", Cuadernos de Estudios Gallegos, 66, núm. 132 (2019), págs. 15-43, https://doi.org/10.3989/ceg.2019.132.01 


\title{
LOS ASENTAMIENTOS RURALES DE ÉPOCA ROMANA EN EL CONTEXTO DEL BAIXO MIÑO: EL YACIMIENTO DE CURRÁS, TOMIÑO
}

\begin{abstract}
RESUMEN
El yacimiento arqueológico de Currás (Tomiño), descubierto en el año 1972, ha sido objeto de nuevos estudios 40 años después. Gracias al proyecto de investigación llevado a cabo entre los años 2013 y 2015, se ha recuperado material gráfico y arqueológico inédito de la primera intervención, y se han documentado en detalle las principales características de este yacimiento, lo que ha permitido obtener una percepción más completa de este asentamiento romano y de su necrópolis tardorromana y altomedieval.

En este artículo presentamos los principales resultados de esta investigación que aporta nuevos datos sobre los asentamientos rurales en el territorio del Baixo Miño y consecuentemente en el Noroeste de la Península Ibérica.

Palabras Clave: villa, necrópolis, territorio, época romana, antigüedad tardía, Gallaecia.
\end{abstract}

\section{OS ASENTAMENTOS RURAIS DE ÉPOCA ROMANA NO CONTEXTO DO BAIXO MIÑO: O XACEMENTO DE CURRÁS, TOMIÑO}

\begin{abstract}
RESUMO
O xacemento arqueolóxico de Currás (Tomiño), descuberto no ano 1972, voltou a ser obxecto de estudio 40 anos despois. Grazas a un proxecto de investigación levado a cabo entre os anos 2013 e 2015 recuperouse material gráfico e arqueolóxico inédito do momento da descuberta, así como se documentaron en detalle as principais características deste xacemento romano e da súa necrópole tardorromana e altomedieval.

Neste artigo presentamos os principais resultados deste estudo que aporta novas consideracións sobre este tipo de asentamentos rurais no territorio do Baixo Miño e consecuentemente no Noroeste da Península Ibérica.

Palabras Clave: villa, necrópole, territorio, época romana, antigüidade tardía, Gallaecia.

\section{RURAL SETTLEMENTS OF THE ROMAN AGE IN THE BAIXO MIÑO AREA: THE ARCHAEOLOGICAL SITE OF CURRÁS, TOMIÑO}

\section{ABSTRACT}

The archaeological site of Currás (Tomiño), excavated in 1972, has been subject to new studies forty years on. New archaeological activities and the discovery of new graphical, oral and material documentation, have given us a new perception of this Roman and medieval settlement and necropolis.

In this article we will present the main results of this research, which provide new data about this type of rural setting at the Baixo Miño territory, and consequently at the NW of the Iberian Peninsula.

KeY wORDS: villa, necropolis, territory, Roman Age, Late Antiquity, Gallaecia. 
Recibido/Received: 03/04/2018

Aceptado/Accepted: 05/02/2019

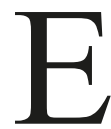

n el ámbito meridional de Galicia, concretamente en el extremo suroccidental de la provincia de Pontevedra, se extiende la comarca del Baixo Miño (Fig. 1), donde el marcado protagonismo que ejerce el río Miño configura un territorio interfronterizo con Portugal de gran interés para el análisis de la ocupación romana en el Noroeste peninsular. Así, en ambas orillas de su tramo final ${ }^{1}$, se documentan abundantes testimonios de la ocupación de este fértil valle, con asentamientos de muy diversa naturaleza adaptados significativamente a dos

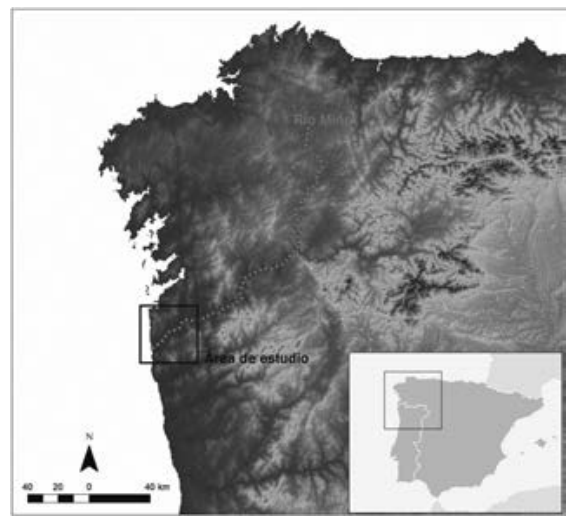

Fig. 1. Localización de la comarca de O Baixo Miño, territorio objeto de este estudio, al SW de Galicia, en la provincia de Pontevedra. factores fundamentales: las vías de comunicación (terrestres y fluviales) y la explotación de los recursos naturales (mineros, fluviales y agropecuarios).

La importancia histórica de este territorio en la Antigüedad aparece ya recogida de forma desigual en las fuentes clásicas ${ }^{2}$, fundamentalmente a partir de la referencia al populus de los Grovios asentado en este contexto geográfico (Mela, III, 10), así como en referencia al núcleo central de este territorio o posible $c a$ put civitatis, en el enclave Tude (Tui): mansio, aglomerado secundario y capital administrativa del ámbito meridional del territorio que actualmente ocupa la provincia de Pontevedra ${ }^{3}$. En efecto, ya desde el siglo I d. C. aparecen menciones

\footnotetext{
1 Espacio correspondiente con los ayuntamientos de Tui, Tomiño, O Rosal y A Guarda, en el ámbito español; y con los municipios de Valença, Vila Nova de Cerveira y Caminha, en territorio portugués.

2 Ana María Romero Masiá y Xosé Manuel Pose Mesura, Galicia nos textos clásicos, A Coruña, Museo Arqueolóxico Provincial, 1987 (Monografías Urxentes do Museu, 3).

3 Fermín Pérez Losada, Entre a cidade e a aldea: estudio arqueohistórico dos "aglomerados secundarios» romanos en Galicia, Brigantium 13, A Coruña, Museo Arqueolóxico de S. Antón, 2002, págs. 6187; Silvia GonzÁlez Soutelo y Marta Cendón Fernández (eds.), Tui, presente, pasado y futuro: I
} 
a este asentamiento, bien por parte de autores grecolatinos como Plinio (Nat. IV, 112), Silio Itálico (III, 366-367) o Ptolomeo (II, 6, 44), bien en las referencias a los ejes viarios establecidos en el Noroeste Peninsular, tanto en las menciones presentes en miliarios (EE VIII 209, de cronología augustea; IRG III 3, de época adrianea), como en las citas a la vía XIX del Itinerario Antonino $(429,4,7)$ o del Anónimo de Rávena $(307,17)$.

Consecuentemente, entendemos que un primer factor para comprender la articulación del Baixo Miño en la Antigüedad será recordar el papel de la mansio Tudae / Tude como enclave de referencia sociopolítica para la ordenación de este territorio, ya no solo en época romana (al menos desde principios del siglo I d. C.) sino con significativa preponderancia en momentos posteriores ${ }^{4}$. Teniendo en cuenta esa población, en torno a ella se ha identificado un significativo número de asentamientos de la edad del hierro y época romana cuya ubicación aparece directamente vinculada con los condicionantes estratégicos, viarios y económicos antes indicados 5 . Si bien no todos los casos han sido suficientemente estudiados ni han sido objeto de intervenciones arqueológicas que ayuden a establecer su cronología y caracterización, sí son testimonio del desarrollo económico y social de las márgenes del Miño en su inclusión en el ámbito cultural del mundo romano.

Coloquio de Historia de Tui, Tui, 2006; Silvia GonzÁlez Soutelo, O Tui antigo: unha aproximación histórica-arqueolóxica. Noia, Toxosoutos, 2007.

4 Cabe recordar el papel que Tude cumplió en época tardorromana y suevo-visigótica, fundamentalmente a partir de su selección como sede episcopal entre los años 561-572 d. C. en el territorio encuadrado a ambas orillas del río Miño, con la asignación de un amplio número de parroquias dependientes de esta sede (citadas en el Parrochiale Suevum). Tude contaría también con una ceca monetaria propia en época suevo-visigótica, actuando como sede temporal de la corte visigótica en época de Witiza (Pierre DAVID, Études historiques sur la Galice et le Portugal du VIe au XIIe siècle, Lisboa, Institut Français au Portugal, 1947, págs. 69-70; Pablo C. DíAz Martínez, El reino suevo (411-585), Madrid, Akal, 2011).

5 Sobre este territorio se han desarrollado diversos estudios interdisciplinares, siendo uno de los más recientes y significativos el realizado por Brais CuRRÁs REFoJos, Transformaciones sociales y territoriales en el Baixo Miño entre la Edad del Hierro y la integración en el Imperio Romano, tesis doctoral inédita, Universidade de Santiago de Compostela, 2014. También, de forma específica sobre este territorio, cabría citar el estudio del territorio del Baixo Miño presentado por Patricia VALLE ABAD, et al., "El yacimiento romano-medieval de Os Medos (Currás, Tomiño). Aproximación a la explotación de un territorio fluvial (Baixo Miño) entre la Antigüedad y la Edad Media”, en Ladislao Castro, Beatriz Comendador, Elena de Uña, Fermín Pérez y Susana Reboreda (eds.), Paisajes culturales del Agua (arqueología, antigüedad y territorio), Ourense, Diputación de Ourense, 2016, págs. 127-136. Para la orilla portuguesa, resaltar la tesis doctoral de Helena Paula Abreu de CARvalHo, O povoamento romano na fachada ocidental do Conventus Bracarensis, tesis doctoral inédita, Universidade do Minho, 2008; o los trabajos previos de Carlos Alberto Brochado de Almeida, A arqueologia proto-histórica e romana no concelho de Vila Nova de Cerveira, Vilanova de Cerveira, s. n., 2000; Carlos Alberto Brochado de AlmeIDA, Povoamento romano no litoral minhoto entre o Cávado e o Minho, Vilanova de Cerveira, 2003, donde cabe llamar la atención sobre el yacimiento del Forte de Lovelhe (Carlos Alberto Brochado de ALMEIDA y Paula Cristina Moreira Ramalho, Memórias arqueológicas do Forte de Lovelhe (1985-2015), Vila Nova de Cerveira, 2015, dada la relación que creemos tiene con el yacimiento de Currás, objeto de este estudio. 
En un análisis preliminar, hemos inventariado cerca de 200 yacimientos de esa cronología, principalmente de tipo habitacional (castros y asentamientos romanos), así como diversas manifestaciones de esa ocupación del territorio ya en época romana, en forma de explotaciones mineras, necrópolis y restos viarios (posibles caminos, puentes y miliarios) con perduración o adaptaciones en época medieval (Fig. 2).
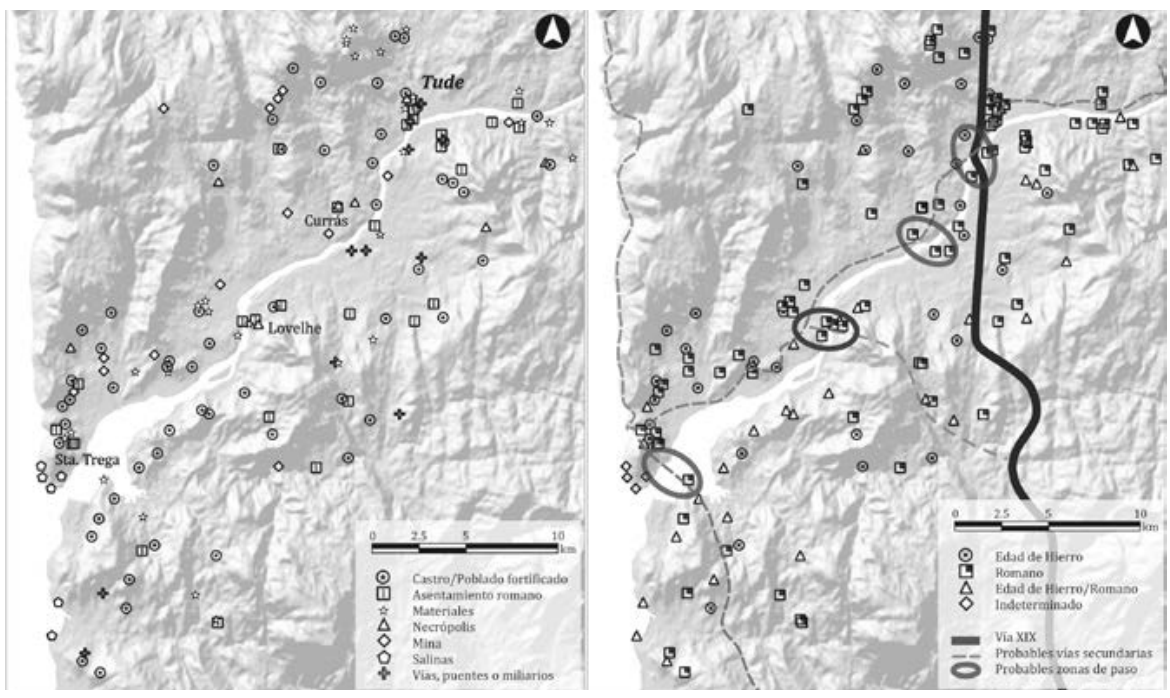

Fig. 2. Mapa del Baixo Miño con la distribución de los yacimientos arqueológicos inventariados en ambas márgenes del tramo final del río Miño, según criterios tipológicos y cronológicos, trazados viarios, así como posibles zonas de paso del río Miño (P. Valle Abad).

El análisis de estas evidencias testimonia, durante ese periodo, un progresivo acercamiento de los asentamientos humanos al río Miño como eje vertebrador de la zona. De hecho, se constata una dinámica en la que la distribución de los castros, situados de forma preminente en zonas altas, con mayor o menor cercanía al río, dan paso a asentamientos romanos más próximos al río y con una cierta linealidad que se justificaría por su adaptación a la presencia de vías de comunicación. En este contexto, además del ya citado enclave Tude (Tui), cabe destacar la existencia de otros asentamientos con probada relevancia para el estudio de este valle, como pueden ser el castro galaicorromano de Sta. Trega (A Guarda) ${ }^{6}$ o el asentamiento romano-tardorromano de Lovelhe (Vila Nova de Cerveira) ${ }^{7}$. Todos ellos muestran

\footnotetext{
6 Una aproximación a los datos de las últimas intervenciones de este castro, con referencias a la bibliografía anterior, puede verse en Rafael M. Rodríguez Martínez, "Re-excavando Santa Trega (A Guarda, Pontevedra). Nuevos datos y conclusiones del Barrio Mergelina”, Férvedes, 9 (2018), págs. 107-116.

7 Véase una revisión actualizada de este yacimiento en Almeida y RAMALHO, Memórias arqueológicas...
} 
una clara vinculación con el río, bien sea por funcionar como puertos, puntos de paso o como enclaves administrativos y de control estratégico y visual del valle.

Tal y como hemos mencionado, la distribución claramente lineal de no pocos asentamientos, o la existencia de explotaciones auríferas con un cierto encaje lineal paralelo al río, nos induce a considerar la presencia de trazados viarios destinados a unir aquellas áreas de ocupación presididas por los asentamientos citados. En efecto, además de la vía principal (vía XIX) que cruza el Miño a la altura de Tude (Tui) y continúa su trazado a través de la depresión meridiana ${ }^{8}$, es necesario plantear la presencia de vías secundarias, entre las que identificamos, con base en la distribución de yacimientos, la toponimia local y la documentación medieval, al menos una vía paralela al río por su banda gallega entre Tui y A Guarda sobre la que enlazarían otros caminos de índole comarcal (caso de la vía costera atlántica) o local (camino que conectaría la vía XIX con la vía secundaria en su trazado entre Tui-A Guarda, tras cruzar el Miño a la altura de Vila Nova de Cerveira).

En esta breve imagen del paisaje antiguo del Baixo Miño, no podemos obviar, como ya se ha citado, la existencia de yacimientos vinculados a la explotación de los recursos naturales de esta zona, donde, además de las salinas de evaporación marina identificadas en la desembocadura del río9, es significativa la riqueza aurífera de este territorio, con explotaciones a cielo abierto sobre los depósitos aluviales del Miño y sus afluentes ${ }^{10}$. Al igual que ocurre en otros distritos mineros del Noroeste peninsular, es de suponer que estas explotaciones auríferas implicaron una profunda transformación y reorganización del hábitat comarcal, y consecuentemente de la economía de la zona, con la inclusión de nuevos modelos de asentamientos y las necesarias infraestructuras viarias para su explotación. No obstante, la producción agrícola y ganadera fue sin duda otro de los ámbitos económicos primordiales y complementarios en un territorio especialmente fértil ${ }^{11}$ y dotado de recursos hídricos, a lo que se uniría la explotación de los recursos marítimo-fluviales, tal y como se evidencia en la cultura material localizada en los yacimientos de esta comarca.

\footnotetext{
8 Si bien no se conoce el punto de paso exacto de la vía a la altura de las poblaciones de Valença y Tui, sí se identifica su trazado aproximado a partir de los restos arqueológicos, los miliarios y la documentación medieval registrada. Para un análisis de esa problemática, remitimos a González Soutelo, $O$ Tui antigo... págs. $115-129$.

9 Recientemente en estudio en el contexto del proyecto "A Guarda, Mar de Sal”, dirigido por B. Currás y M. Cortegoso.

${ }^{10}$ Brais X. Currás Refojos, y Luís F. López González, "Minería romana y poblamiento en la cuenca

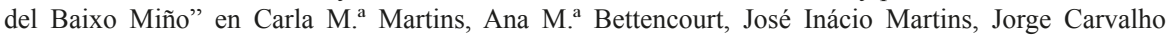
(coords.), Povoamento e exploraçâo dos recursos mineiros na Europa Atlántica occidental, Braga (2011), págs. 179-202.

11 Brais X. Currás Refojos, "Mapa de usos potenciales de la tierra de Galicia. Una perspectiva arqueológica", Trabajos de Prehistoria, 71, 1 (2014), págs. 23-41.
} 
En ese contexto de progresiva explotación y humanización del territorio en época romana, uno de los yacimientos arqueológicos que sin duda ha de contribuir a la compresión diacrónica de las dinámicas vividas en esta comarca es el asentamiento romano-tardorromano y necrópolis altomedieval de Currás (Tomiño). $\mathrm{Si}$ bien es cierto que estamos ante una fase inicial del proyecto de $\mathrm{I}+\mathrm{D}$ propuesto para la recuperación y revalorización de este yacimiento tomiñés ${ }^{12}$, los resultados obtenidos a partir del estudio de los testimonios escritos, gráficos y orales, así como del análisis de las estructuras y de los materiales localizados tanto en el momento de su descubrimiento (1972) como en la reciente intervención arqueológica (2013), muestran algunas claves que ayudarán a comprender el desarrollo histórico del valle del río Miño entre la Antigüedad y la Edad Media.

\section{El YACIMIENTO DE CURRÁS (TOMIÑO): LOCALIZACIÓN}

El yacimiento de Currás, ubicado en la parroquia del mismo nombre (ayuntamiento de Tomiño) (Fig. 3), fue localizado en 1972 por el Equipo Arqueológico del Baixo Miño de forma casual a partir de un estudio sobre toponimia ${ }^{13}$. Por medio de una pequeña intervención arqueológica realizada en los meses de verano de ese mismo año y bajo la dirección de Francisco Fernández Rodríguez ${ }^{14}$, se descubrió, en los lugares de Os Medos y O Adro, lo que se identificó con una villa romana y una necrópolis tardorromana y medieval. Tras la intervención, los restos fueron nuevamente enterrados aunque afortunadamente quedó testimonio de dicha intervención en el breve artículo publicado unos años más tarde ${ }^{15}$, trabajo que ha sido hasta el momento la base fundamental de conocimiento sobre este enclave. Según la descripción presentada en dicha publicación, el yacimiento se caracterizaría por la presencia de un edificio compuesto por diversas estancias, algunas de ellas dotadas de hipocausto, en cuyas proximidades se identificó una construcción compartimentada que fue considerada como área de almacén o de servicio. Por último, en la parte alta de la colina inmediata al yacimiento se localizó

\footnotetext{
12 Proyecto de I+D titulado Oxacemento de Currás (Tomiño): Proxecto para a investigación, recuperación e posta en valor dun patrimonio arqueolóxico 'non'esquecido dirigido por F. Pérez Losada y S. González Soutelo, del GEAAT de la Facultade de Historia de la Universidad de Vigo. Para más información sobre el planteamiento del proyecto véase Silvia González Soutelo, et al., "40 anos dun descubrimento. Crónica da investigación arqueolóxica sobre o xacemento romano e altomedieval de Currás, Tomiño (1972-2013)", Castellum Tyde. Revista do Instituto de Estudios Tudenses, 4 (2013-2014), págs. 33-58.

13 Jesús Gómez Sobrino, et al., "La villa romana y necrópolis germánica de Currás-Tomiño", Boletín del Museo Diocesano de Tui, 3 (1980), págs. 323-324.

${ }^{14}$ Investigador oriundo de la vecina parroquia de Goián (Tomiño) y comisario local de Excavaciones, que fue director, entre los años 1950 y 1960, de los trabajos arqueológicos en el castro Sta. Trega (A Guarda). Xoán Martínez de TAmuxe, Citania y museo arqueológico de Santa Tecla, A Guarda, Patronato Municipal del Monte Santa Tecla, 1998, pág. 34; Currás Refojos, "Transformaciones sociales y territoriales en el Baixo...", pág. 144.

15 Gómez SoBrino, et al., "La villa romana y necrópolis...”, págs. 321-338.
} 

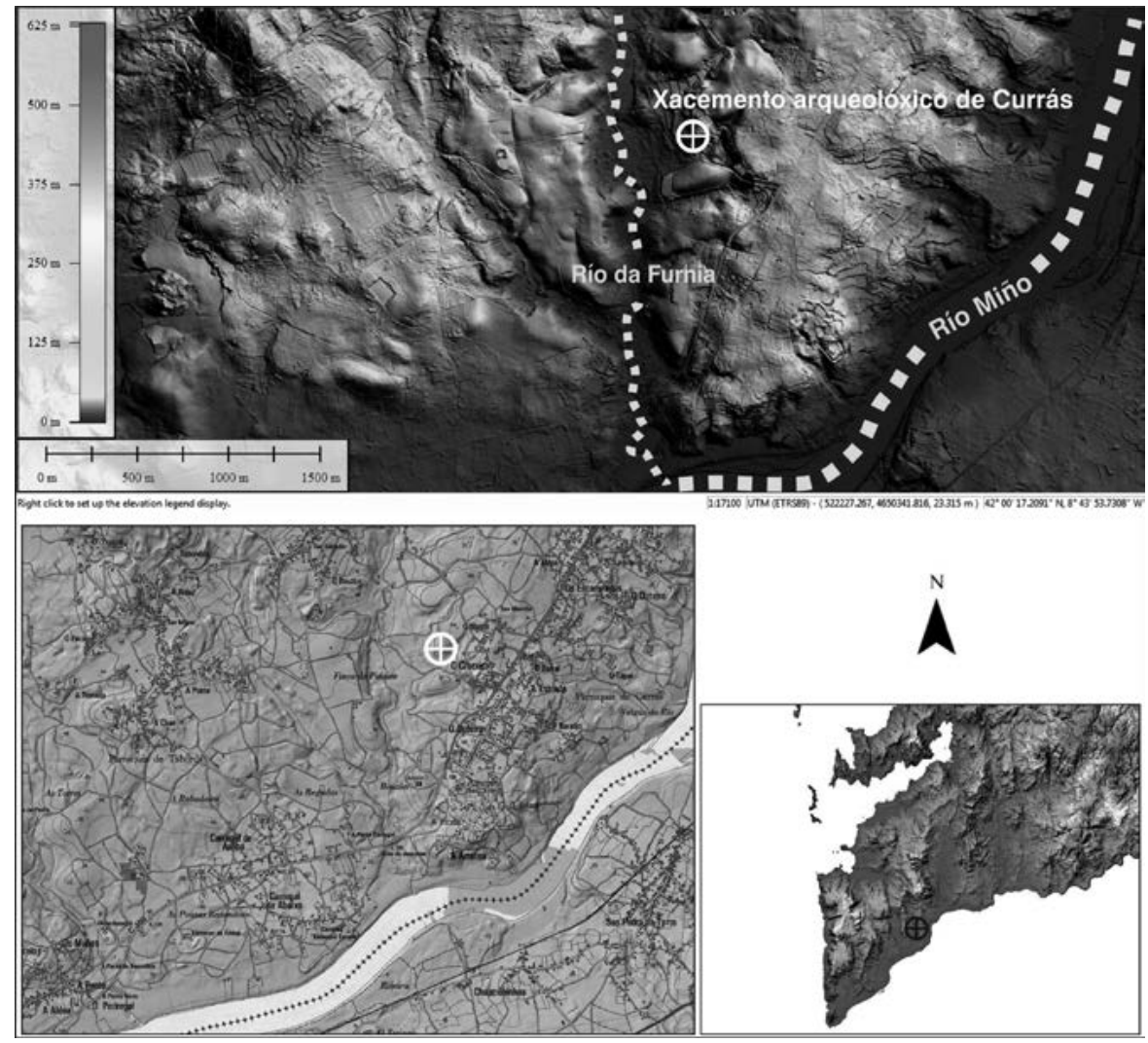

Fig. 3. Localización del yacimiento arqueológico de Currás (Tomiño).

un amplio número de enterramientos (contabilizando hasta 40 sepulturas de las que se excavaron un total de 20), que en función de su tipología y de los materiales empleados, se interpretaron como de época tardorromana /suevo-visigoda ${ }^{16}$.

Tras la sucinta descripción realizada en dicha publicación, el análisis de este yacimiento daba lugar a múltiples interrogantes (sobre su localización, la naturaleza de estas construcciones y su cronología), por lo que en 2013 se llevó a cabo una breve intervención con la que se pudo constatar la entidad constructiva de ese enclave, y recopilar nuevos datos sobre su ubicación (Fig. 3), funcionalidad y configuración, a la espera de futuras actuaciones que puedan dar una visión más amplia y completa sobre este yacimiento.

16 Ibíd. 


\section{DESCRIPCIÓN Y NUEVOS DATOS}

El yacimiento se localiza en un terreno de marcado desnivel, con dos áreas principales de ocupación: la designada como "villa" (sita en la parte inferior del terreno, lugar de Os Medos) y la necrópolis (parte superior, lugar de Adro) (Fig. 4). Si bien en la descripción del yacimiento aparece la referencia a la presencia de un castro en el lugar ${ }^{17}$, hasta el momento no existe prueba alguna que justifique la existencia del pretendido poblado fortificado de la edad del hierro, más allá de la constatación puntual de material romano adscribible, como veremos, al siglo I d. C.

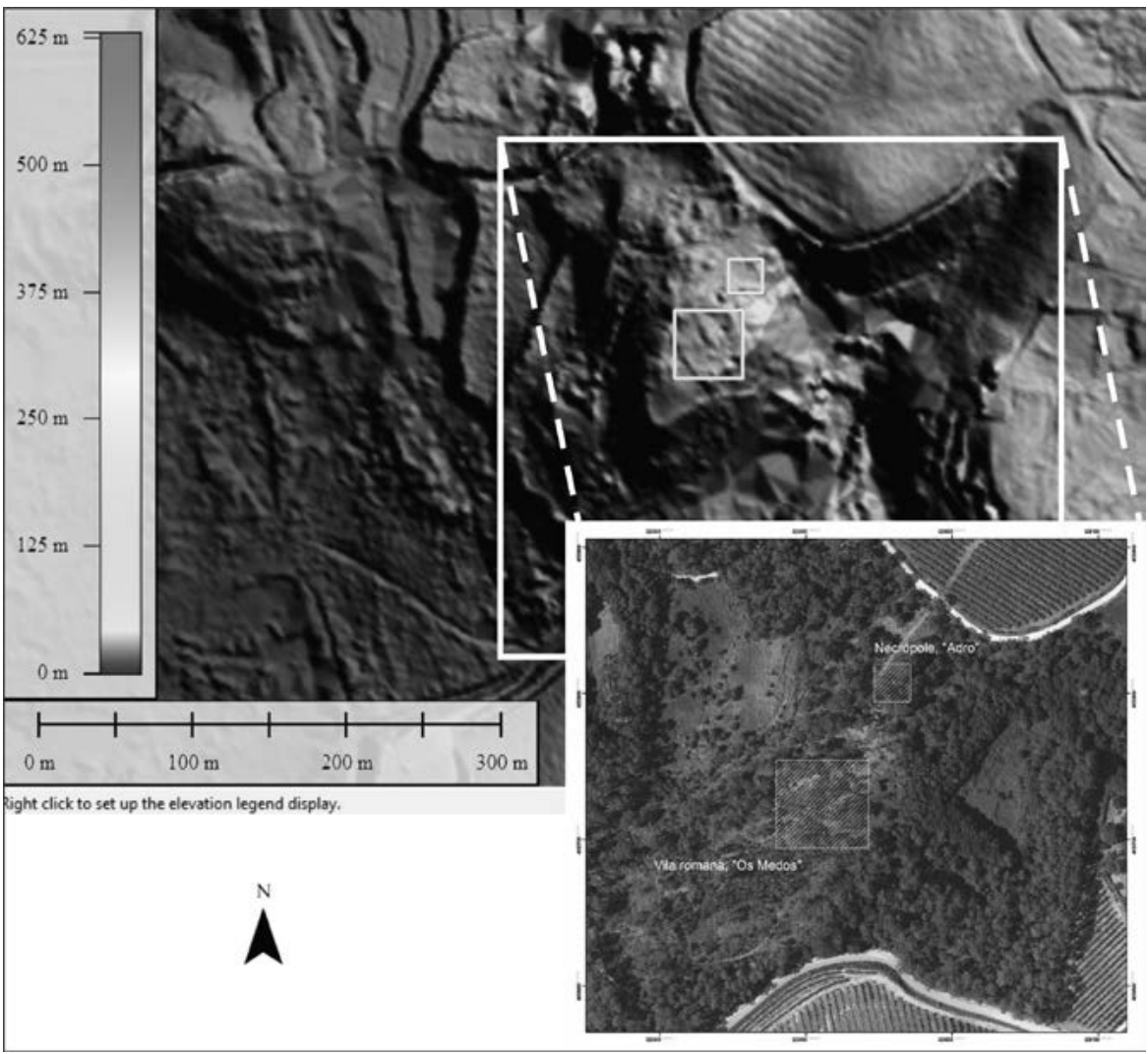

Fig. 4. Identificación topográfica sobre mapa MDT obtenido a partir de datos LIDAR y fotografía aérea -PNOA- de las dos áreas arqueológicas del yacimiento: al Norte, necrópolis de O Adro; y al Sur, villa de Os Medos.

\footnotetext{
${ }^{17}$ Así aparece mencionado en distintos lugares del citado artículo, Gómez Sobrino, et al., "La villa romana y necrópolis...", pág. 326: "El castro se asienta sobre una terraza cuaternaria...", "Este castro está situado...", "En la cima del castro Medos está situada una necrópolis de grandes dimensiones...".
} 


\section{VILLA}

En el sector inferior del espacio que ocupa el yacimiento de Currás, designado en el catastro antiguo ${ }^{18}$ como "Os Medos", nos encontramos ante una edificación principal, que abarcaría, de acuerdo con el espacio arqueológico que pudimos estudiar, una superficie aproximada de $150 \mathrm{~m}^{2}$ (10.6 x $\left.14 \mathrm{~m}\right)$, orientada de Este-Oeste, ampliable en su lado SW.

Con planta sensiblemente rectangular (Fig. 5), por su fachada oriental se reconoce el punto de acceso a las instalaciones, atravesando el umbral constituido por un bloque monolítico de granito de buena calidad en el que se identifican los rebajes longitudinales para el ajuste de la puerta (Fig. 6). Es probable que este punto de acceso situado al E contase con un atrio porticado ${ }^{19}$, de acuerdo con los fragmentos de fuste descubiertos en la intervención arqueológica de 1972 y posteriormente reenterrados, de los que se ha recuperado al menos una parte tras la reciente actuación arqueológica de 2013.

Desde esta entrada se daría acceso a dos estancias (sala N: 7.3 x 5.6 m.; sala $\mathrm{S}$ : 5 x $5.6 \mathrm{~m}$ ), pavimentadas con tierra arcillosa, con una división medianera que solo se evidencia por la presencia de una breve alineación de piedras irregulares sobre la cimentación en la roca madre. Ambas estancias podrían ser interpretadas como espacios domésticos de índole habitacional o incluso como áreas de actividad productiva, tal como parecen apuntar algunos materiales aparecidos en estas salas ${ }^{20}$.

Estas estancias orientales estarían separadas de las salas anexas con hipocausto ubicadas al Oeste (con orientación Norte-Sur) por medio de un muro de sillería irregular de buena calidad de $50 \mathrm{~cm}$ de ancho (Fig. 7). En el sector Oeste, por tanto, se detectan tres divisiones o salas con hipocausto de diferentes dimensiones (de Norte a Sur: 1.6 x $3.6 \mathrm{~m}$; 1.8 x $3.6 \mathrm{~m} ; 2.5$ x $3.6 \mathrm{~m}$, respectivamente), cuya area presenta vanos de comunicación realizados con sillares de granito de buena calidad y grandes dimensiones $(1.4 \times 0.45 \mathrm{~m})$.

Las tres salas del hipocausto presentan un area realizada con ladrillos pedales (29-30 cm de lado) y sesquipedales (de $45 \mathrm{~cm}$ de lado), sobre la que se colocan pilae de ladrillos bessales (de 18-20 cm de lado), alguna de ellas con hasta 4 ladri$1 \operatorname{los}^{21}$ de altura conservada in situ, sustentadas sobre una base de ladrillos pedales, lo que daría una altura total máxima conservada de $44 \mathrm{~cm}$. A continuación, hacia

\footnotetext{
${ }^{18}$ Catastro de la riqueza rústica de Pontevedra, Partido judicial de Tui, término municipal de Tomiño, polígono 89 , fotografías $52 \mathrm{~A}$ y $52 \mathrm{~B}$.

${ }^{19}$ La orientación del edificio permitiría proteger la entrada al edificio de los vientos del Norte, facilitando así unas condiciones óptimas de habitabilidad y confort.

${ }^{20}$ Gómez Sobrino, et al., "La villa romana y necrópolis...”, pág. 336, y tal y como pudimos documentar a partir del estudio de los materiales localizados (8 pesas de telar, cerámica común y sigillata).

${ }^{21}$ En las fotografías de 1972, la pila más alta aparece con 5 ladrillos bessales, por lo que el ladrillo que falta debe corresponder al ejemplar depositado en el museo Diocesano de Tui.
} 


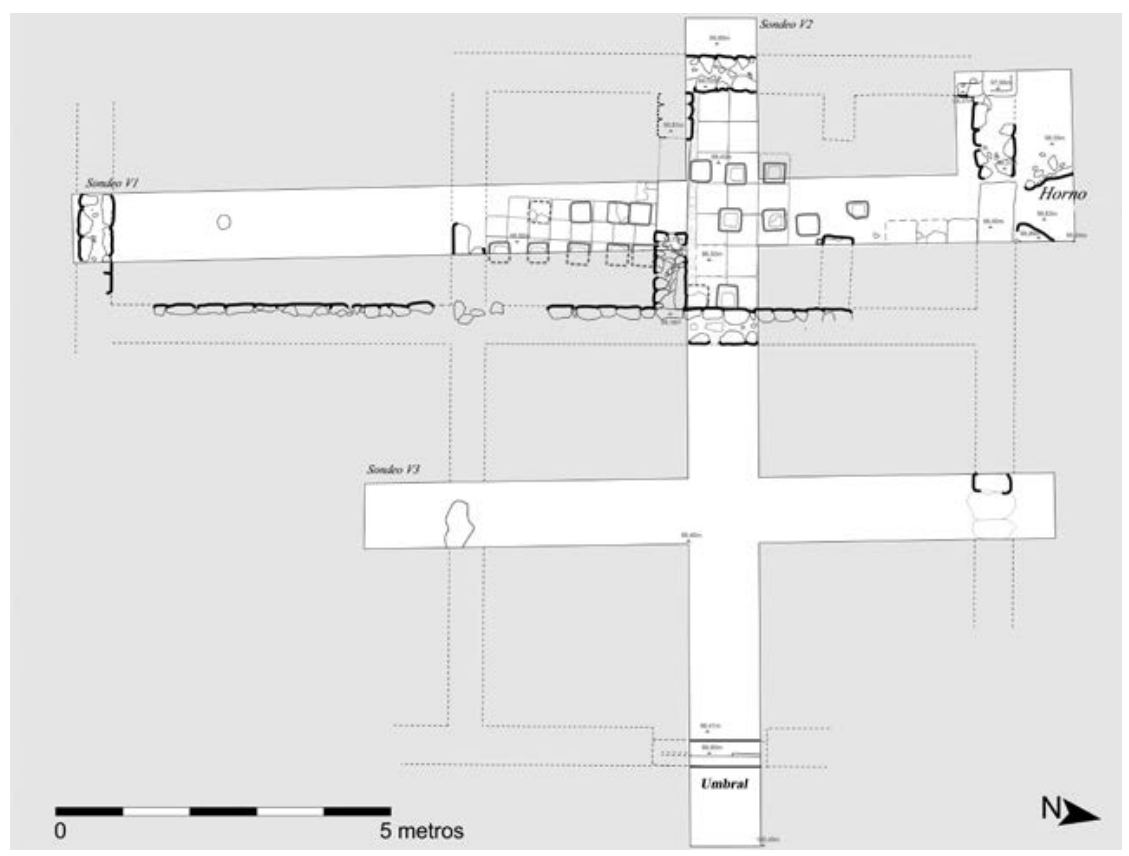

Fig. 5. Planta de los sondeos realizados en el área de la villa, con el hipocausto situado al $\mathrm{W}$ del edificio.

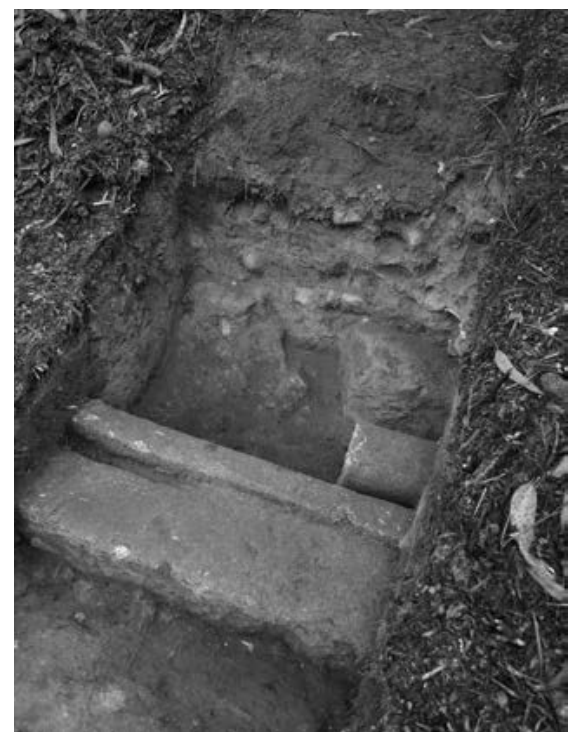

Fig. 6. Fotografía en detalle del umbral de entrada al edificio de la villa.

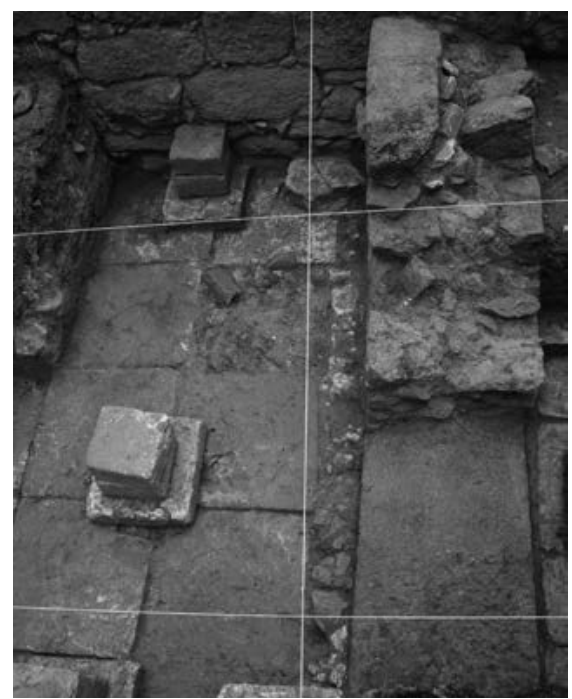

Fig. 7. Fotografía de detalle de parte del hipocausto conservado y muro divisorio con las estancias situadas al este del edificio de la villa. 
el Sur, pero ya fuera de las salas de hipocausto, se localizaría una última estancia (de $5 \times 3.6 \mathrm{~m}$ ) de funcionalidad incierta, con suelo de tierra batida y el negativo de un poste de madera en su centro, por donde parece continuar el edificio.

En relación con el hipocausto, gracias a la intervención realizada en 2013, se pudo documentar puntualmente una parte inédita del yacimiento, situada en un pequeño sector al Norte del conjunto, correspondiente con la estructura del horno que calefactaría las salas (Fig. 8). Dicho horno estaba construido con muros de delimitación pétrea de factura sencilla, configurando una boca de $0.5 \mathrm{~m}$ de ancho en donde se identifica la parte correspondiente al espacio de combustión (praefurnium), así como el espacio anexo de depósito de las cenizas en los procesos de limpieza del horno. Debido a lo limitado de la intervención, no se pudo completar su excavación en área, aunque sí fue posible recoger in situ un fragmento cerámico de TSBT rojiza perteneciente a una gran fuente de la Forma $7,{ }^{22}$ que ha permitido adscribir el momento de abandono de este horno hacia finales del siglo IV - principios del siglo V d. C. Esa cronología ha podido ser confirmada

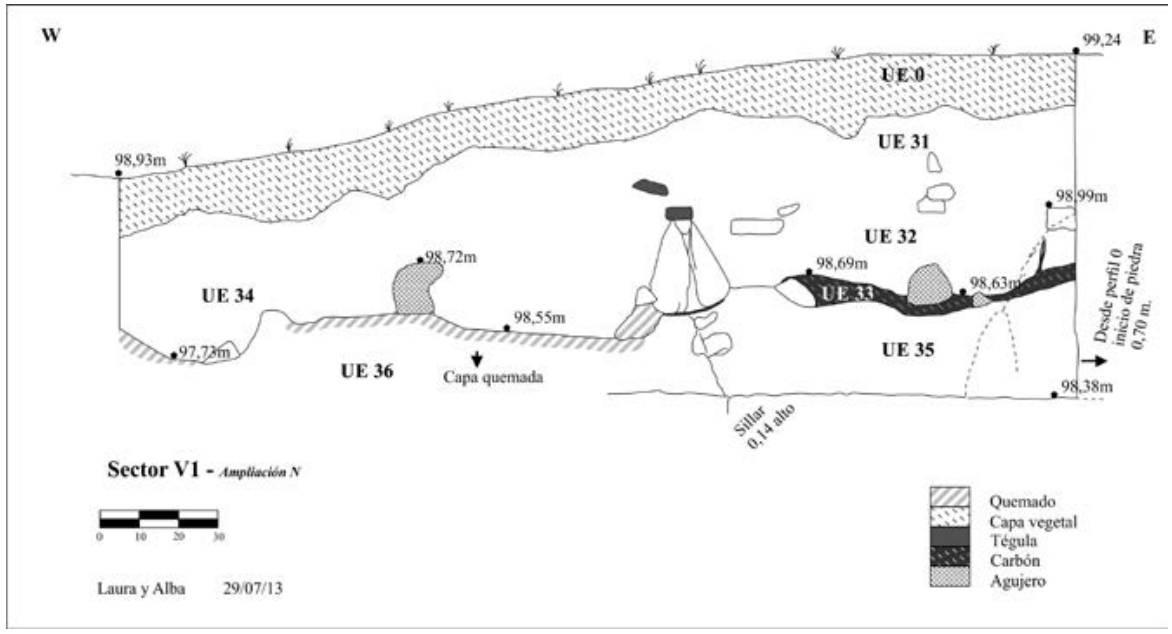

Fig. 8. Sección estratigráfica del perfil Norte del sondeo V1, donde se localizó el horno del hipocausto y se tomó la muestra de carbón para su análisis por C14.

\footnotetext{
${ }^{22}$ Estudiado por A. Fernández Fernández, y publicado en Fermín Pérez Losada y Silvia GonzÁLEz Soutelo, Tomiño romano: o xacemento de Currás [exposición], Tomiño, s. n., 2014, págs. 52-54), con paralelos significativos, por ejemplo, en el caso de la villa romana de Toralla, Vigo (Adolfo FERnÁNDEZ, Fermín Pérez y Santiago Covela, "Cerámica fina de importación en Toralla (Vigo): abastecimiento y consumo en una villa costera atlántica tardorromana”, en Carmen Fernández Ochoa, Virginia García-Entero y Fernando Gil Sendino (eds.), Las «villae» tardorromanas en el occidente del Imperio: arquitectura y función, Coloquio Internacional de Arqueología en Gijón (Gijón, 2006), Gijón, Trea, 2008, págs. 575 586).
} 
por el análisis de C14 del material carbonizado localizado en dicho horno que mantenía intacta la disposición estratigráfica original ${ }^{23}$.

En la fase actual de la investigación no ha sido posible identificar la configuración completa de este edificio, ya que en el ámbito Sur es posible que esta estructura se prolongase más allá del muro Oeste y Sur del hipocausto, al menos en el sector correspondiente a la sala de pavimento de tierra batida situada al Suroeste del complejo ${ }^{24}$. Igualmente desconocemos cómo sería la prolongación de esa sala hacia el Sureste (¿posible espacio de entrada auxiliar y sala funcional?), lo que permitiría definir el tamaño definitivo de este edificio, así como la articulación y funcionalidad de sus estancias.

Por el contrario, sí tenemos el indicio de cómo sería el cierre Noroeste de la construcción principal, ya que dentro de la ampliación que se realizó del sondeo V1 en su lado Norte, se pudo testimoniar el punto de unión entre la UM01 y la UM02 en el rebaje que se aprecia en la roca madre. Por tanto, en ese cierre se ha podido documentar el negativo de un gran sillar, extraído ya en época antigua, que serviría a modo de esquinal de la construcción por este lado NW.

Por último, el hallazgo durante la excavación de 1972 de varios ejemplares de grapas de hierro en T o doble T, junto con un ladrillo de los denominados "de entalle", actualmente expuesto en el Museo Diocesano de Tui ${ }^{25}$, permite suponer que las estancias calefactadas por hipocausto contaban con paredes y bóvedas huecas (concamerationes), creando así las necesarias cámaras de aislamiento térmico y dispositivo anti-humedad tan características de los espacios termales romanos. No obstante, resulta difícil certificarlo, puesto que las piezas recuperadas son muy escasas, y ninguna de ellas ha sido recuperada en contexto.

Independientemente de que las estancias calefactadas estuvieran cubiertas con bóveda o no, todo el conjunto del edificio iba tejado con tegulae e imbrices de los que aparecieron multitud de fragmentos, tanto en 1972 como en 2013. Muchas de estas tejas llevan marcas digitadas, tanto las consabidas combinaciones circulares como otras de carácter alfabetiforme entre las que podemos identificar

\footnotetext{
${ }^{23}$ Analítica realizada en los laboratorios Beta Analytic Inc. de Florida en noviembre de 2014, con los resultados siguientes: fecha radiocarbónica convencional: 1690 +- 30 BP; fecha calendárica calibrada (2 sigma, $95 \%$ de probabilidad): 255-295 d. C. y 320-415 d. C.; fecha media de interceptación de la edad radiocarbónica con la curva de calibración: 380 d. C.

${ }^{24}$ Durante los sondeos realizados en Julio de 2013, se realizó una pequeña ampliación en el sondeo V2 al Oeste de la UM01 para intentar comprobar si existía suelo antrópico, con resultados negativos.

${ }^{25}$ Estos materiales constructivos han sido descritos y estudiados en PÉrez LoSADA y GonzÁLEz SouteLO, Tomiño romano... págs. 44-47. El ladrillo de entalle, de 4 muescas, se corresponde con el tipo 5a de Bouet (Alain Bouet, Les matériaux de construction en terre cuite dans les thermes de la Gaule Narbonnaise, Talence, Ausonius, pág. 101).
} 
al conocido artesano $R V F(\text { us/inus })^{26}$. En 1972 también apareció un fragmento de tegula ocularis que podría vincularse tanto a ese posible espacio termal, como a áreas de actividades domésticas, permitiendo la ventilación y salida de humos de cocinas o talleres.

\section{OTROS ESPACIOS ANEXOS A LA EDIFICACIÓN PRINCIPAL}

Aunque durante la intervención de 1972 se excavaron restos significativos de estructuras identificadas como una hipotética área rústica de uso agropecuario (caso de las estancias con pequeñas divisiones que pudieron haber funcionado como almacenes o espacios de servicio ${ }^{27}$ ), lo cierto es que durante los sondeos llevados a cabo en 2013 no fue posible su localización concreta en el conjunto del yacimiento.

En todo caso, la existencia de estas estructuras podría indicar un patrón de distribución dispersa de varias construcciones de distinta funcionalidad en las inmediaciones del edificio habitacional principal. De hecho, en la inmediata finca denominada "Tomada dos Pinos" hay indicios arqueológicos que parecen revelar la presencia de una hipotética estructura de combustión (¿un horno de cerámica de construcción?), donde está prevista una próxima intervención arqueológica ${ }^{28}$.

\section{NECRÓPOLIS}

En el caso de la necrópolis los datos con los que trabajamos son muy escasos. A pesar de que gracias a la publicación de Gómez Sobrino, et al. publicada en 1980, que cuenta con un plano esquemático sin escala en el que se recoge una breve descripción de aquellas tumbas más representativas y más próximas a la cima de la colina, son pocos los indicios que nos permiten establecer una datación o valoración de los materiales asociados a ella más allá de las escuetas notas publicadas.

A partir de los sondeos realizados en 2013 se localizaron e identificaron cuatro de las tumbas excavadas anteriormente - con la consecuente posibilidad de escalar la necrópolis- (Fig. 9). Los enterramientos descubiertos presentan la canónica orientación cristiana Noroeste-Sureste, aunque, el uso de diferentes materiales constructivos reutilizados (piedra, ladrillo y tegula), así como su gran variedad tipológica, podrían estar indicando a grandes rasgos una diferenciación cronológica. Según la información publicada en $1980^{29}$, se localizaron así tumbas de

\footnotetext{
${ }^{26}$ La marca de alfarero $R V F$ sobre cerámica de construcción es conocida también en Bande y Riocaldo (estampillada), así como en el castro de Vigo, Alobre y A Coruña (digitada). Véase en PÉrez LosADA y GonzÁlez Soutelo, Tomiño romano... págs. 42-43.

27 Gómez Sobrino, et al., "La villa romana y necrópolis...”, pág. 331.

28 Agradecemos al arqueólogo territorial de Pontevedra, Xulio Carballo Arceo, la referencia a este hallazgo y a su futura intervención arqueológica.

${ }_{29}$ Gómez SoBrino, et al., "La villa romana y necrópolis...”, págs. 326-331.
} 
tegulae con cubierta a dos aguas, de tipo caballete o capuchina (no detectadas en los recientes sondeos, pero sí documentadas en fotografías), que se vincularían a la primera etapa de esta necrópolis, directamente relacionada con la fase de ocupación del asentamiento o bien con un momento inmediatamente posterior a su abandono.

Sin embargo, la mayoría de los enterramientos parecen estar vinculados a una segunda fase de la necrópolis. Fundamentalmente los enterramientos asociados a esta fase estarían realizados con mampostería granítica, llamando la atención el hecho de que al menos uno de ellos estaba cubierto, a modo de tapa, por una piedra circular de molino, con perforación central, fragmentada en dos bloques.

De las tumbas reexcavadas en 2013, correspondientes a las situadas más al

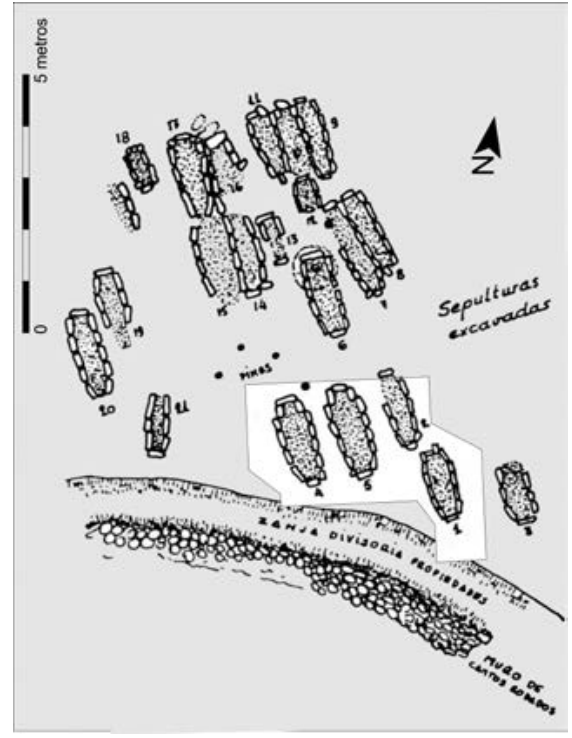

Fig. 9. Planta de la necrópolis identificada en 1972 (a partir de Gómez Sobrino, et al., "La villa romana y necrópolis..."), con detalle de las 4 tumbas reexcavadas en 2013, e inclusión de escala y orientación de esta parte del yacimiento. Sur del conjunto identificado en 1972

(Fig. 10a y 10b), tres enterramientos son fusiformes o antropomorfos, realizados con demarcación de piedras de granito hincadas en la tierra (posiblemente reaprovechados de las construcciones del lugar), con medidas variables, siendo la de mayor tamaño de 1.8 x $0.5 \mathrm{~m}$. La tumba realizada íntegramente con ladrillos rectangulares, en su mayoría fragmentados, cuenta con unas dimensiones interiores de 1.3 x $0.35 \mathrm{~m}$, y una profundidad conservada de $0,28 \mathrm{~m}$., realizada directamente sobre el terreno original.

Dado que estábamos ante enterramientos ya excavados, pocos datos significativos se pueden aportar sobre el material asociado a estas tumbas ${ }^{30}$. Uno de los aspectos más mencionados por la bibliografía posterior al citar este yacimiento, fue la puntual referencia a la aparición de objetos vinculables al mundo visigodo (caso de una hebilla de hierro y un aplique con decoración vegetal ${ }^{31}$ ).

\footnotetext{
${ }^{30}$ En la publicación de 1980, al describir las tumbas reexcavadas en 2013, se indica específicamente que no apareció ningún material asociado a esos enterramientos, salvo en el caso de la tumba situada más al Oeste, donde solo se menciona la constatación de escorias en el lugar, aspecto que ha podido ser verificado.

${ }^{31}$ De esta pieza, no hemos localizado ninguna fotografía o dibujo que permita reconocer su naturaleza. Gómez Sobrino, et al., "La villa romana y necrópolis ...", pág. 331. Sobre la presencia de estos objetos
} 

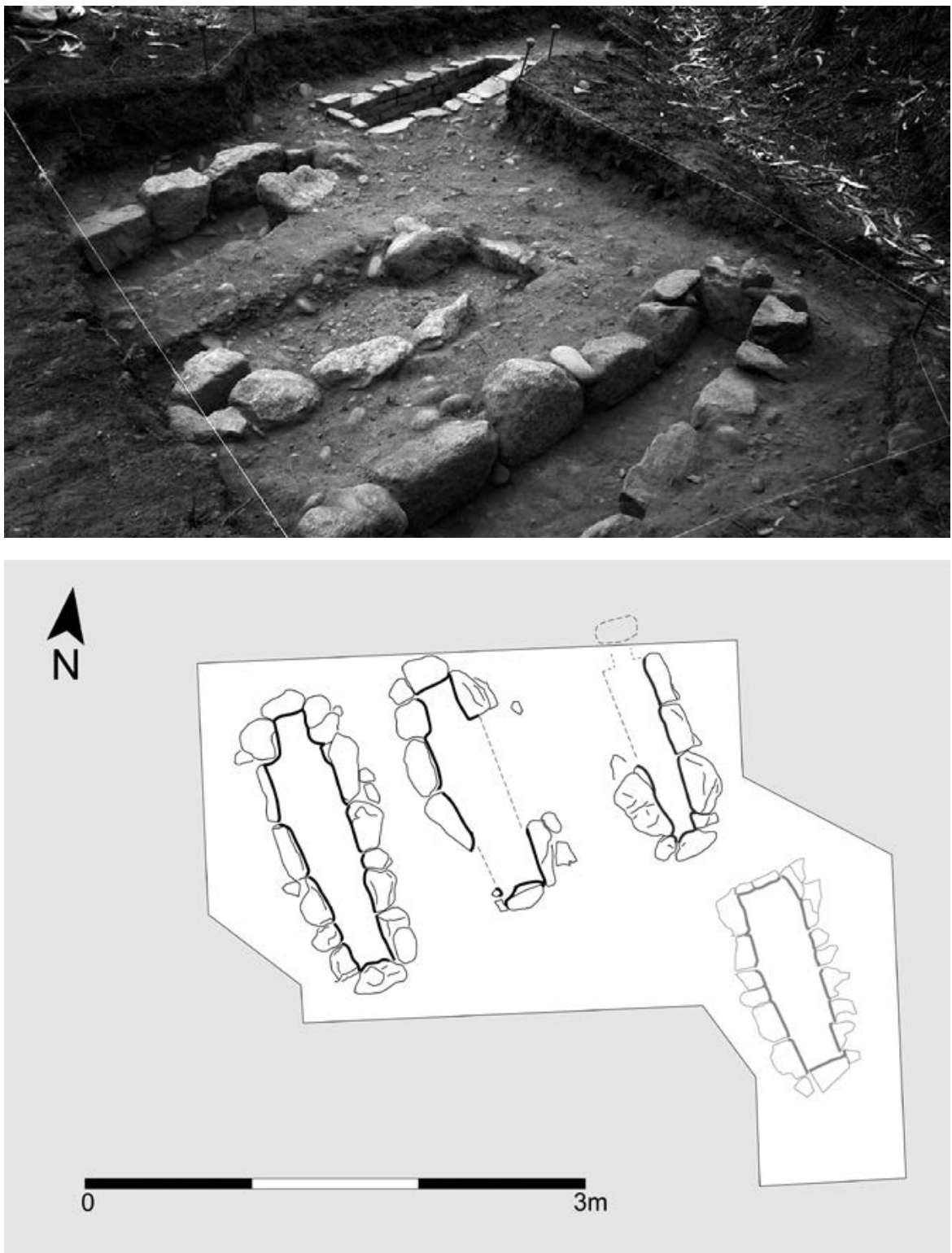

Fig. 10a y 10b. Planta y fotografía de las tumbas localizadas en 2013.

aislados, es muy limitada la información que puede obtenerse, más allá de que, como indica Alexandra ChaVARria ARnaU, "El final de las villas y las transformaciones del territorio rural en el occidente (siglos V-VIII)», )", en C. Fernández Ochoa, V. García Entero y F. Gil Sendino (eds.), Villas tardorromanas en Hispania, IV Coloquio Internacional de Arqueología de Gijón (Gijón, 2006), Gijón, Trea, 2008, pág. 75: 
Desafortunadamente, no se conservan las piezas descritas, aunque sin duda, la cronología más probable para esta necrópolis se correspondería con el periodo atribuido a la ocupación del NW por parte de población germánica, tanto a partir de la tipología de las tumbas descubiertas como de la cultura material indicada por sus descubridores.

A esos materiales vinculados a los enterramientos se une la presencia de un pequeño grupo de escorias (posibles restos de sangrado de metal de ¿hierro?), algunas de ellas inicialmente localizadas in situ debajo de las piedras hincadas que forman la delimitación de los enterramientos. Sorprende en todo caso la presencia de esos residuos de producción, que en último caso podrían estar haciendo referencia a una hipotética área metalúrgica previa, de la que solo contamos con indicios circunstanciales en un área ya intervenida y, por tanto, sujeta a múltiples condicionantes que dificultan su interpretación.

\section{CONSIDERACIONES SOBRE EL YACIMIENTO ROMANO DE CURRÁS EN SU CONTEXTO CRONOLÓGICO, TEMPORAL Y ESPACIAL. SU SIGNIFICADO TERRITORIAL}

Como ya hemos indicado, el yacimiento romano y altomedieval de Currás se localiza a escasos $7 \mathrm{~km}$ al Oeste de la ciudad romana de Tude (Tui), en el trayecto que enlazaría este enclave con la desembocadura del río Miño en el Océano Atlántico. En ese contexto de cercanía a uno de los enclaves romanos más significativos del ámbito meridional de la actual Galicia, el yacimiento de Currás es uno de los escasos asentamientos rurales propiamente romanos y de larga duración que se han reconocido hasta el momento en el ámbito del Baixo Miño ${ }^{32}$.

Si analizamos la ubicación específica de este yacimiento, comprobamos que se aúnan diversos criterios estratégicos:

a) Se localiza en posición dominante sobre el paso de una probable vía secundaria $^{33}$ que, desde el interior, seguiría el cauce del río Miño hasta su desembocadura en el espacio costero del Suroeste de Galicia. A través de este trazado viario delimitado por el río Miño, el yacimiento de Currás se encuentra bien comunicado, por una parte, con el entramado viario principal (vía XIX del It. Ant.), así como

\footnotetext{
"aportan solo una evidencia de la amplia dispersión y comercio de estos materiales y de la progresiva militarización y barbarización de la cultura material y de la sociedad a partir de finales del siglo IV d. C.".

$32 \mathrm{Si}$ bien se han identificado yacimientos en el entorno del Baixo Miño que se han interpretado como pequeños casales o villae a partir de materiales superficiales, solo contamos con un limitado número de enclaves arqueológicos excavados, entre los que destacan el de Currás o el de Lovelhe, para comprender la romanización del espacio rural en este tramo final del Baixo Miño.

${ }^{33}$ En ese sentido aparecen las referencias a una vía de comunicación de cierta entidad en época medieval (Elisa Ferreira Priegue, Los caminos medievales de Galicia. Boletín auriense, anexo 9, Ourense, Museo Arqueolóxico Provincial, 1988 , págs. 82-83), que podría corresponder con un tramo viario de época anterior.
} 
con el eje fluvial, donde el tramo navegable del río Miño sería una vía indudable de importación y exportación de mercancías ${ }^{34}$, tanto en el intercambio entre una orilla y otra del río, como en la consecuente navegación desde y hacia el ámbito marítimo ${ }^{35}$ (Fig. 11).

b) Otro factor esencial será la explotación de los ricos recursos naturales presentes en este tramo final del río Miño. Así, por una parte, cabe señalar la inmediatez a los ejes fluviales del Furnia y el Miño como fuente de recursos ya no solo desde el punto de vista comercial, sino también como espacios para la explotación fluvial (pesca y derivados) y de abastecimiento de agua; así como la riqueza productiva del territorio en el que se asienta ${ }^{36}$, tanto en la faceta agropecuaria (sobre todo en la fase tardía del yacimiento, al que se vinculan las estructuras conservadas), como en su probable relación temprana con las recientemente descubiertas explotaciones mineras de filones de oro en depósitos secundarios ${ }^{37}$, que podrían justificar su inicial fundación en el territorio que nos ocupa.

En efecto, los materiales arqueológicos más tempranos apuntan a una posible primera ocupación altoimperial del lugar de Currás ya desde el siglo I d. C., cronología que, si se confirma, podría ponerse en relación con la emergencia y consolidación de las explotaciones auríferas de la comarca. De hecho, el yacimiento se encuentra relativamente próximo de las cortas mineras auríferas de Carregal y Tomada Blanca, e incluso no sería descartable considerar que la profunda depresión situada inmediatamente al Sur-Sureste del yacimiento, significativamente denominada "Fonte da Moura" por la presencia de una mina de agua en el lugar, pudiese formar parte de dicha explotación aurífera romana, aspecto que consideramos deberá tenerse en cuenta en futuros estudios.

Desde una perspectiva microtopográfica, apreciamos igualmente una posición estratégica del enclave romano dentro del espacio natural que ocupa. Situado a $1.5 \mathrm{~km}$ al Norte del río Miño y al Este del río Furnia, la villa romana de Currás

\footnotetext{
${ }^{34}$ Como aparece claramente reflejado en el registro material analizado en este yacimiento (PÉREz LoSADA y GonzÁlez Soutelo, Tomiño romano...) incluyendo abundantes y significativas importaciones mediterráneas y orientales; o en yacimientos de la orilla vecina como el enclave portuario de Lovelhe, en Vila Nova de Cerveira (Almeida y Ramalho, Memórias arqueológicas do Forte...); Almeida, A arqueologia proto-histórica...).

${ }^{35}$ Posición estratégica de espacio portuario y barcas de pasaje en época medieval y con posterioridad (ver, al respecto, Ernesto IGLESIAS AlmeIda y Plácido MÉndez Cruces, Evocación histórica de la ciudad de Tui y sus antiguas rúas, Tui, 1997, págs. 64-74). Ver también la nota anterior.

${ }^{36}$ Dentro de los estudios sobre el análisis de los espacios productivos en Galicia (CuRrás RefoJos, "Mapa de usos potenciales..."), el yacimiento de Currás se localiza en una de las áreas más amplias y de mayor aprovechamiento agrícola del territorio circundante a la ciudad de Tui.

37 Sobre los hallazgos de explotaciones mineras antiguas, especialmente auríferas, en el tramo final del Baixo Miño, véase una síntesis en Currás Refojos y López González, "Minería romana y poblamiento...", Currás Refojos, Transformaciones sociales y territoriales..., o Almeida, A arqueologia proto-histórica...
} 


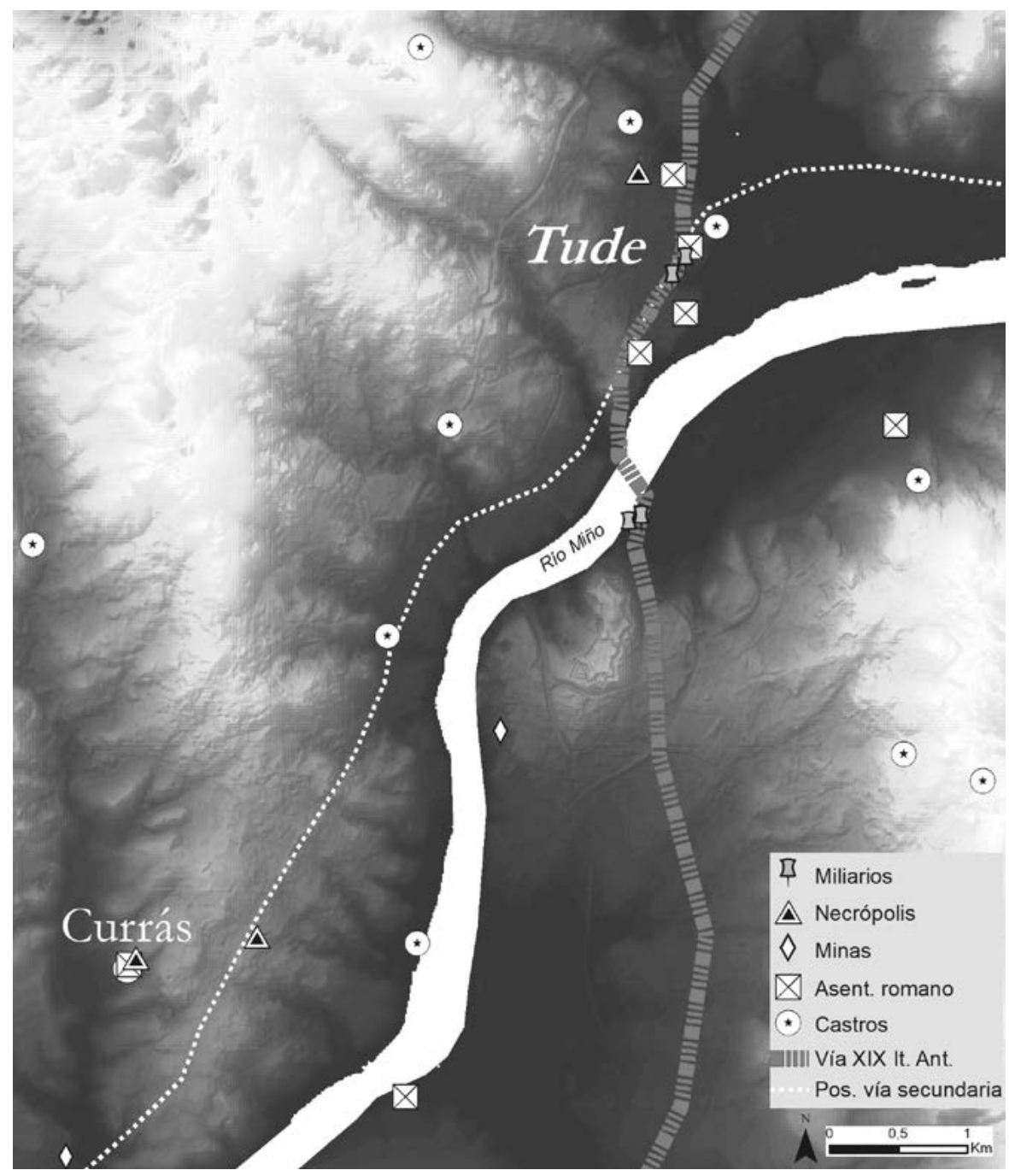

Fig. 11. Ubicación del yacimiento de Currás respecto a la población de Tui (Tude), el río Miño y el trazado N-S de la vía XIX del It. Antonino. Incluimos el desarrollo de la posible vía secundaria con un trazado paralelo al río Miño.

se ubica en una pequeña colina ${ }^{38}$ con un marcado desnivel que protegería al yacimiento del viento del Noreste-Este. En este ámbito tendrían cabida, ya no solo la

${ }_{38}$ Aspectos que recomiendan agrimensores como Varrón (I, 12, 1), en relación a las ubicaciones ideales de las villae, tal y como recoge M. ${ }^{a}$ Cruz Fernández Castro, Villas romanas en España, Madrid, Dirección General de Bellas Artes, Archivos y Bibliotecas, 1982, págs. 41-51. 
edificación dotada de estancias con hipocausto, sino una serie de construcciones funcionales $\mathrm{u} / \mathrm{o}$ habitacionales anexas que vendrían a completar el conjunto.

La necrópolis vinculada al asentamiento, con el que pudo haber convivido durante un limitado periodo de tiempo a juzgar por la tipología constructiva de algunos de los enterramientos, se desarrollaría mayoritariamente tras el abandono de esas instalaciones, dada la reutilización de los materiales procedentes de las construcciones del lugar. Situada en un espacio algo apartado del área residencial y en la planicie superior de la colina ${ }^{39}$, ocupa, sin un orden aparente, toda una amplia superficie que aprovecha la suave vertiente de la colina hacia el Noroeste.

El topónimo original de esta área de necrópolis, designada en el catastro antiguo como "Adro", y que recuerda, salvando las distancias, lo que sucede en otros yacimientos gallegos de cronología similar o dotados de necrópolis en contextos próximos (pensemos por ejemplo en el yacimiento de Adro Vello-S. Vicente de O Grove- ${ }^{40}$ o A Lanzada -Sanxenxo- ${ }^{41}$ ), podría sugerir la presencia de un eremitorio o capilla primitiva ${ }^{42}$ aún no localizada, que reforzaría la idea de la ubicación en este lugar de la primera sede parroquial de S. Martín de A Gándara ${ }^{43}$. En todo caso, la pervivencia de este espacio en fechas posteriores a la del asentamiento inmediato,

\footnotetext{
${ }^{39}$ Como parece repetirse en otros ejemplos de necrópolis próximas. Véase X. Miguel GonzÁLEz FeRNÁNDEZ, "Las tumbas romanas de Galicia", Pontevedra Arqueológica II (1986), pág. 213.

${ }^{40}$ Estudiada principalmente por Manuel Carlos García MartíneZ y José Manuel VÁzQuez Varela, "La Necrópolis de "Adro Vello" (San Vicente de O Grove)", Compostellanum 13, 4 (1968), págs. 563-571; y José Carro Otero, "Los esqueletos bajo-romanos de San Vicente de "O Grove", Cuadernos de Estudios Gallegos 26, 79 (1971), págs. 129-153.

${ }^{41}$ Para un estado de la cuestión sobre esta necrópolis, ver principalmente los trabajos publicados por Antonio Blanco FreiJeiro, Miguel Fusté Ara y Alfredo García Alén, "La necrópolis galaico-romana de La Lanzada (Noalla, Pontevedra)", Cuadernos de Estudios Gallegos, 16 (1961), págs. 141-153; Antonio Blanco Freijeiro, Miguel Fusté Ara y Alfredo García Alén, "La necrópolis galaico-romana de La Lanzada (Noalla, Pontevedra) II”, Cuadernos de Estudios Gallegos, 22 (1967), págs. 5-23; Antonio Blanco Freijeiro, Miguel Fusté Ara y Alfredo García Alén, "La necrópolis galaico-romana de La Lanzada (Noalla, Pontevedra). II. Conclusiones”, Cuadernos de Estudios Gallegos, 22 (1967), págs. 129155; José Carro Otero, M. a del Carmen Masa Vázquez y M. a Luisa Varela Ogando, "Un nuevo enterramiento en la necrópolis galaico-romana de La Lanzada (Noalla-Pontevedra)", Pontevedra Arqueológica II (1986), págs. 229-252; con la actualización de la investigación, en: Olalla López-Costas y Tito VArela López, "Estudio craneométrico comparativo de los esqueletos de la necrópolis romana de A Lanzada, Noalla, Pontevedra", Museo de Pontevedra, 62 (2008), págs. 29-48; Rafael RodríGuEz MARTíNEZ, et al., Intervención arqueolóxica para a recuperación patrimonial do xacemento de A Lanzada, Informe valorativo, Pontevedra, 2010; Rafael RodríGuez MArTínez, "O sitio arqueolóxico da Lanzada a través dos seus materiais", en Sanxenxo na historia, volume IV: Arte, patrimonio e mundo rural, Santiago de Compostela, Galicia Milenio, 2015, págs. 269-86.

42 Tendencia presente en otras áreas del Imperio, en las que se van creando capillas o eremitorios asociados a antiguas villae (Jorge LóPEz Quiroga, "Después del "final” de las villae entre el Miño y el Duero (ss. VII-X): comunidades "fructuosianas", hábitat rupestre y "aldeas"”, CuPAUAM, 31-32 (2005-2006), pág. 225).

43 Gómez Sobrino, et al., "La villa romana y necrópolis...”, pág. 322.
} 
no deja de evidenciar la diacronía de la ocupación humana de este territorio hasta la alta edad media, documentándose también en la necrópolis localizada en 1953 en las proximidades de la actual iglesia parroquial de S. Martiño de Currás ${ }^{44}$, a poco más de 700m de distancia en línea recta del yacimiento que nos ocupa.

El otro microtopónimo del yacimiento, Os Medos, podría relacionarse de nuevo con las explotaciones mineras, quizás, tal y como hemos indicado, vinculado al desnivel y destierre existente al Sur del yacimiento que podría haber sido provocado por un movimiento antrópico del terreno (¿mina romana?). En ese mismo contexto, el espacio central de esta depresión está ocupado por la Fonte da Moura, mina de agua a la que se le asocian leyendas transmitidas por los vecinos del lugar ${ }^{45}$ en relación con los mouros-mouras u otros seres del imaginario popular que muy frecuentemente están relacionadas con yacimientos arqueológicos (mámoas, minas o castros) ${ }^{46}$.

\section{ÁMBITO CRONOLÓGICO Y CULTURAL}

A partir del estudio de la cultura material del yacimiento (tanto la procedente de las excavaciones de 1972 y que fue depositada en el Museo Diocesano de Tui, como la recuperada en la reciente intervención de $2013^{47}$ ), y del análisis de la estratigrafía original del yacimiento obtenida durante esta última campaña, podemos presentar unas primeras consideraciones a nivel cronológico que contextualizan el yacimiento de Currás en su entorno.

La presencia de materiales arqueológicos relativamente antiguos, claramente altoimperiales, tales como fragmentos de ánforas itálicas (Dressel 1) y béticas (Haltern 70), o bien de vajilla fina de mesa de producción hispánica (TSH: Drag. $15 / 17)^{48}$, permiten proponer una fase inicial del yacimiento entre los siglos I-III d. C., datación acorde con el desarrollo de este territorio en época romana altoimperial, tanto por la fundación del enclave Tude ${ }^{49}$ posiblemente en época

\footnotetext{
${ }^{44}$ Manuel Fernández RodríGuez, "Una necrópolis de tipo romano en Currás (Pontevedra)", en Homenaje al profesor Cayetano de Mergelina, Murcia, Universidad de Murcia, 1962, págs. 329-331.

45 Avelino Bouzón, "Los vestigios arqueológicos en Currás (Tomiño)", Faro de Vigo, edición Baixo Miño / Louriña (25-10-1995), pág. 4.

${ }^{46}$ Mar Llinares García, Os Mouros no imaxinario popular galego, Santiago de Compostela, Universidade, Servicio de Publicacións, 1990.

${ }^{47}$ Descripción y estudio de los principales materiales arqueológicos, realizado por diversos especialistas, en Pérez losada y González Soutelo, Tomiño romano...

${ }^{48}$ El único fragmento localizado de Dres. 1 es característicamente tardorrepublicano, datable probablemente en el siglo I a. C. Los escasos fragmentos de ánforas béticas (Halt.70, operculum) están datados en el siglo I d. C. Más abundantes son los hallazgos de TSH (una docena de platos de la forma Drag.15/17), producidos seguramente durante el siglo II o incluso los inicios del III d. C. Véase Pérez LosADA Y GoNZÁlez Soutelo, Tomiño romano..., págs. 52-53 y 58-59.

49 Según las menciones citadas en la introducción, así como en relación con los distintos materiales arqueológicos identificados en el contexto de la ciudad y sus inmediaciones. Para una descripción de las
} 
augustea o julio-claudia, como por el establecimiento de uno de los ejes viarios más importantes del Noroeste ${ }^{50}$. En ese contexto, podríamos sugerir la presencia de una ocupación galaico-romana dedicada a la explotación del territorio, quizás enfocada a la organización y control de las explotaciones mineras auríferas que se implantan en el Baixo Miño desde el siglo I d. C., en donde se testimonian los primeros contactos comerciales de importación marítima.

En todo caso, a pesar de esos primeros indicios de época temprana, la inmensa mayoría del material estudiado apunta a una segunda y principal ocupación de este yacimiento en época bajoimperial-tardorromana, donde, quizás el progresivo abandono de la actividad minera a partir del siglo IV d. C. provocaría la readaptación del asentamiento y de sus funciones hacia la esfera agropecuaria y posiblemente comercial. En efecto, nos encontramos ante un yacimiento con un marco cronológico bastante definido (siglos IV-VI d. C. principalmente), tal como confirman los materiales cerámicos (ánforas orientales tardías, terra sigillata focense tardía, terra sigillata bracarense tardía roja y gris, lucernas tipo candil, cerámica común gris tardía, cerámicas micáceas tardías hechas a mano) y vítreos (botellas y cuencos tardíos) ${ }^{51}$. Sin embargo, el proceso de abandono del asentamiento empezaría a producirse ya a finales del siglo IV o inicios del $\mathrm{V} \mathrm{d}$. C., como lo reflejaría los hallazgos producidos en contexto estratigráfico original, detectándose el abandono y deterioro parcial de esta construcción a partir de esa fecha o bien, al menos, el final del funcionamiento de parte de sus estructuras.

A pesar de este relativamente temprano desuso o abandono de parte de la construcción descubierta, el asentamiento perviviría probablemente durante los siglos V y VI, en plena época de dominio político suevo-visigótico, como bien indican las sigillatas focenses (TSFT), las bracarenses tardías grises (TSBT) ${ }^{52}$ o las ánforas orientales tardías (LRA) ${ }^{53}$ aparecidas en las diferentes intervencio-

evidencias localizadas y de la principal bibliografía al respecto, ver PÉrEz LosADA, Entre a cidade e a aldea...; GonzÁLEz Soutelo, O Tui antigo...

${ }^{50}$ Trazado viario posiblemente de época augustea, con posteriores reformas, a juzgar por la datación más temprana documentada en los miliarios de esta vía del Itinerario Antonino (Antonio RodríGuez ColmeNero, Santiago Ferrer Sierra y Rubén Álvarez Asorey, Miliarios e outras inscricións viarias romanas do noroeste hispánico, Lugo, Consello da Cultura Galega, 2006).

${ }^{51}$ Los materiales cerámicos han sido estudiados por A. Fernández y los vítreos por M. Xusto (a quienes agradecemos encarecidamente su colaboración), publicados en Pérez Losada y GonzÁlez Soutelo, Tomiño romano... págs. 48-63.

${ }^{52}$ De TSFT fueron recuperados dos platos de la forma Hayes 3, uno de ellos decorado con la figura estampillada de un ciervo. De TSBT de color gris destaca la presencia de grandes platos o fuentes, uno de ellos con el borde perlado, así como varios ejemplares de los típicos cuencos carenados. Todas las piezas están datadas preferentemente en el siglo VI d. C., aunque en algún caso podrían remontar a finales del V o bien llegar incluso hasta inicios del VII (Pérez Losada y GonZÁlez Soutelo, Tomiño romano ..., págs. 52-55).

${ }_{33}$ Varios fragmentos de Late Roman Amphorae (LRA), tipos 1, 2 y 3, procedentes de diversas zonas del Mediterráneo Oriental (Cilicia-Siria, Éfeso-Sardis o Sur del Egeo) y con cronologías igualmente centra- 
nes en el yacimiento. Se detecta incluso la presencia de un tipo de producción alfarera denominada "cerámicas micáceas de tradición castreña hechas a mano", que podría llegar a alcanzar plenamente el siglo VII d. C. ${ }^{54}$ Esta cronología tan característicamente "germánica" (siglos V-VII d. C.) coincidiría con la datación propuesta para la tipología de enterramientos presentes en la necrópolis ${ }^{55}$, cuyo uso funerario continuaría funcionando tras el abandono de la villa, llegando seguramente hasta la alta Edad Media.

Esta amplia sucesión cronológica -asentamiento bajoimperial que perdura, con transformaciones, en época suevo-visigótica- no resulta nada extraña en el ámbito del Noroeste peninsular, sobre todo en la Gallaecia meridional ${ }^{56}$ y específicamente en la zona del Baixo Miño, donde también se documenta en otros enclaves galaico-romanos como pueden ser la propia ciudad de Tui o el vecino poblado y asentamiento portuario de Lovelhe ${ }^{57}$.

\section{TIPOLOGÍA DEL ASENTAMIENTO, BASES SOCIOECONÓMICAS Y CARACTERIZACIÓN FUNCIONAL}

Como hemos indicado, por tanto, las principales estructuras edilicias que se han conservado en el yacimiento se vinculan claramente a ese periodo bajoimperial- tardorromano. Si bien es cierto que su identificación como villa en el sentido clásico de la palabra ${ }^{58}$ debe ser tomada con la necesaria cautela dado el reducido tamaño del área (re)excavada, su escasa monumentalidad y lo limitado de los

das en el s. VI (Pérez Losada y González Soutelo, Tomiño romano..., págs. 60-61).

${ }^{54}$ De esta cerámica común de cocina, característica de las Rías Baixas, se conocen en Currás algunos ejemplares de "potes", una de las formas más típicas de esta producción (PÉREz LosAda y GonZÁLEZ Soutelo, Tomiño romano..., págs. 48-50).

${ }^{55}$ Los enterramientos realizados en piedra, especialmente los de modelo antropomorfo, suelen datarse según sus paralelos como de época germánica y plenamente altomedieval (GonZÁLEz FERnÁndez, "Las tumbas romanas...”, pág. 211).

${ }^{56}$ López Quiroga, "Después del "final” de las villae..."; Almeida, A arqueologia proto-histórica...; Carlos Alberto Ferreira de AlmeidA, “Arqueoloxía tardorromana e germánica no NW peninsular", en Galicia, da romanidade á xermanización: problemas históricos e culturais. Actas do encontro cientifico en homenaxe a Fermín Bouza Brey, Santiago de Compostela, 1993, págs. 191-200.

57 Yacimiento en el que se ha constatado la progresiva evolución ocupacional del sitio: poblado castreño de finales de la edad del hierro (siglo II a. C.) que se extiende y amplía por el exterior de las murallas en época galaicorromana, con destacadas construcciones bajoimperiales (siglo IV d. C.) que perviven y se transforman hasta, al menos, inicios del siglo VIII d. C. (Almeida y Ramalho, Memórias arqueológicas do Forte..., pág. 166).

${ }_{58}$ Sobre los conceptos tipológicos de los asentamientos rurales desarrollados en el Imperio romano y su complejidad terminológica y arqueológica, fundamentalmente en la tardoantigüedad, véase, entre otros, Fermín PÉRez LosAdA, "Sobre o concepto de "villa" no mundo romano", Cadernos de arqueologia, serie II, 4, 1987, págs. 79-108; o José Ignacio Martínez Melón, "El vocabulario de los asentamientos rurales (siglo I-IX d. C.): Evolución de la terminología”, en Alejandra Chavarría, Javier Arce y Giorgo Brogiolo (eds.), Villas Tardoantiguas en el Mediterráneo Occidental, Anejos de Archivo Español de Arqueología, 39, 2006, págs. 113-32), y para el caso concreto del Noroeste Peninsular, Fermín Pérez LosAdA, "Hacia 
vestigios arqueológicos asociados, estaríamos en todo caso ante un establecimiento rural para la explotación y aprovechamiento del territorio inmediato ${ }^{59}$, consistente principalmente en una edificación de reducidas dimensiones con muros de cierre y refuerzos de sillares en los esquinales, que estaría dotada de un sistema de hipocausto de buena factura constructiva para calefactar un pequeño sector del edificio.

La interpretación de este espacio calefactado tampoco es sencilla, ya que si bien los elementos analizados apuntan hacia un espacio termal privado de trazado lineal simple siguiendo el modelo identificado en yacimientos próximos ${ }^{60}$, el número, disposición y tamaño de las salas ${ }^{61}$, la presencia de elementos que permiten proponer la existencia de una concameratio (ladrillos de entalle, grapas de hierro), así como algunos elementos vinculados a la presencia de agua (canal cerámico), surgen ciertas dudas interpretativas sobre la funcionalidad y configuración de este espacio respecto al resto del edificio. De hecho, esta interpretación no concuerda bien con el carácter aparentemente habitacional y funcional de las estancias anexas (piso térreo, presencia de pondera y cerámica común), por lo que no descartamos que pudiese tratarse de espacios residenciales domésticos

una definición de los asentamientos rurales en la Gallaecia”, en Carmen Fernández Ochoa (ed.), Los finisterres atlánticos en la antigüedad: época prerromana y romana, Gijón, Electa, 1996, págs. 189-197.

${ }^{59}$ La problemática para poder definir arqueológicamente una villa es un tema recurrente en la bibliografía (PÉrez Losada, "Sobre o concepto de “villa”...”; Fernández Ochoa, Salido y Zarzalejos, "Las formas de ocupación rural...”, pág. 119), puesto que las referencias presentes en las fuentes clásicas incluyen bajo ese concepto una amplia gama de instalaciones rurales que irían desde una simple granja hasta una lujosa vivienda, normalmente suburbana, de grandes propietarios asentados en ámbito rural. En este caso, consideramos que nos encontramos ante un modelo de villa o villula (MARTínEz Melón, "El vocabulario de los asentamientos...") de desarrollo sencillo, mínimamente acomodada pero carente de aparato decorativo y con instalaciones poco monumentales (según el modelo planteado en PÉREZ LosADA, "Hacia una definición de los asentamientos...", pág. 194), supeditada a la explotación de un fundus.

${ }^{60}$ Especialmente identificados en villae rurales o domus urbanas. Véase un resumen de los principales espacios dotados con hipocausto en Galicia en Fermín PÉREz LoSADA, "Hipocaustos na Galicia romana", Gallaecia, 13, 1992, págs. 129-175; GonzÁlez Soutelo, El valor del agua .... El paralelo más próximo es el de la villa de Toralla en Vigo (Fermín Pérez LosADA, et al., "Toralla y las villas marítimas de la Gallaecia atlántica: emplazamiento, arquitectura y función”, en Carmen Fernández Ochoa, Virginia García-Entero y Fernando Gil Sendino (eds.), Las «villae» tardorromanas en el occidente del Imperio: arquitectura y función, Coloquio Internacional de Arqueología en Gijón (4º. 2006. Gijón), Gijón, Trea, 2008, págs. 481-506.

${ }^{61}$ La parte calefactada del pretendido balneum adopta el esquema más común y repetido de las pequeñas villae, esto es, el plan lineal simple con circulación retrógrada. Las tres cámaras consecutivas de hipocausto probablemente se correspondieron con una estancia calefactada única en la parte superior, dotada de, como mínimo, un alveus o bañera de agua caliente ubicada justo a la salida del horno, de la que infelizmente no se encuentran restos. Esta estructura termal es muy similar a la de las villae de Toralla, Noville o Riocaldo, aunque en estos casos las salas son de mayor tamaño y sí se conservan vestigios arqueológicos de las bañeras. El balneum de Currás es más pequeño, aunque podría compararse con los documentados en algunas domus privadas del Noroeste, por ejemplo, en la ciudad de Lucus Augusti (caso del hipocausto de la calle Cregos. Covadonga CARREÑo GASCón, "Baños privados y termas públicas en el Lugo romano", M. ${ }^{a}$ J. Peréx Agorreta, y A. Bazzana (coords.), Espacio, Tiempo y Forma, Serie II, Hª Antigua, T. V. Casa de Velázquez. UNED, 1992, págs. 337-350; PÉrez LosadA "Hipocaustos na Galicia romana..."). 
calefactados "en seco" mediante hipocausto, aunque la falta de datos, el reducido tamaño de las estancias y los materiales descubiertos en la excavación de 1972 no parecen apuntar hacia esa consideración.

Igualmente, lo limitado de la intervención de campo (tanto en la excavación originaria de 1972 como en la re-excavación de 2013) dificultan la posibilidad de concretar la tipología planimétrica general del asentamiento. Únicamente podemos indicar que aparentemente obedece al tipo de "plan diseminado", es decir, el conformado por varias edificaciones e instalaciones independientes que se localizan próximas unas de otras, adaptándose a la topografía del lugar y a las necesidades residenciales y productivas del asentamiento.

Por el contrario, la cultura material de este yacimiento sí nos habla con certeza del carácter habitacional y doméstico del conjunto, primando obviamente los objetos y utensilios vinculados con la alimentación y el aprovisionamiento de recursos primarios ${ }^{62}$. También resulta significativa la presencia de materiales cerámicos foráneos procedentes del circuito hispánico, mediterráneo y atlántico ${ }^{63}$, que fueron importados tanto a través de la red marítima-fluvial como terrestre, y que nos testimonian la llegada y consumo en el yacimiento de productos de lujo como los vinos traídos desde el ámbito bético o incluso desde el extremo oriental del Mediterráneo. Al igual que sucede en Currás, en los últimos años se ha identificado en todo el tramo de desembocadura del río Miño, al menos hasta la ciudad de Tui hasta donde el río era navegable, materiales arqueológicos que estarían haciendo alusión a la existencia de una importante red comercial en la zona sobre todo en época tardía ${ }^{64}$.

En todo caso, dada su ubicación a escasos kilómetros de la antigua población Tude es muy probable que este enclave estuviese fuertemente condicionado por la presencia de este asentamiento en las proximidades, por lo que, de alguna for-

\footnotetext{
${ }^{62}$ Abundante y significativa presencia de cerámica común de cocina, mesa y almacenamiento, entre la que se encuentran platos-sartenes (de engobe rojo o gris), cuencos y jarras de engobe rojo, morteros, ollas de cerámica micácea de tradición castreña; tinajas para almacenar el grano o un posible asador de castañas o quesero. Esta dedicación agropecuaria que se documenta en la cultura material posiblemente esté reflejando la riqueza productiva de este territorio.

${ }^{63}$ Las piezas importadas consisten en vajilla fina de mesa (TSH, TSBT, TSFT) y algunas ánforas mayoritariamente vinarias (Dr.1, Halt.70, LRA 1, 2 y 3). Estos y otros materiales fueron estudiados por A. Fernández Fernández y publicados en Pérez Losada y González Soutelo, Tomiño romano....

${ }^{64}$ Juan NAveiro LóPez, El Comercio antiguo en el N.W. peninsular: lectura histórica del registro arqueológico, Brigantium 5, A Coruña, Castillo de San Antón, 1991, con indicación específica a la ciudad de Tui, págs. 138-139; y, más recientemente, Adolfo Fernández Fernández, O comercio tardoantigo no Noroeste Peninsular: unha análise da Gallaecia sueva e visigoda a través do rexistro arqueolóxico. Noia: Toxosoutos, 2013. En relación con los asentamientos rurales y la presencia de ese material importado véase LóPEz Quiroga, "Después del “final” de las villae...”. Sobre los asentamientos portuario-comerciales del Baixo Miño, además del probable puerto en Tude, destacan de nuevo las instalaciones portuarias recientemente excavadas en el asentamiento citado de Lovelhe (Almeida y RAMALHo, Memórias arqueológicas do Forte..., págs. 65-71).
} 
ma, cabría vincular su propiedad y/o explotación por individuos asociados a esta población, con la que con total seguridad se establecerían relaciones de comercio y dependencia, para el uso y consumo de los bienes producidos.

\section{BIBLIOGRAFÍA}

Almeida, Carlos Alberto Brochado de, A arqueologia proto-histórica e romana no concelho de Vila Nova de Cerveira, Vilanova de Cerveira, s. n., 2000.

Almeida, Carlos Alberto Brochado de, Povoamento romano no litoral minhoto entre o Cávado e o Minho. Vilanova de Cerveira, s. n., 2003.

Almeida, Carlos Alberto Brochado de y Ramalho, Paula Cristina Moreira, Memórias arqueológicas do Forte de Lovelhe (1985-2015), Vila Nova de Cerveira, s. n., 2015.

Almeida, Carlos Alberto Ferreira de, "Arqueoloxía tardorromana e germánica no NW peninsular", en Galicia: da romanidade á xermanización: problemas históricos e culturais. Actas do encontro científico en homenaxe a Fermín Bouza Brey, Santiago de Compostela, Museo do Pobo Galego, 1993, págs. 191-200.

Blanco Freijeiro, Antonio, Fusté Ara, Miguel y García Alén, Alfredo, "La necrópolis galaico-romana de La Lanzada (Noalla, Pontevedra)", Cuadernos de Estudios Gallegos, 16 (1961), págs. 141-153.

Blanco Freijeiro, Antonio, Fusté Ara, Miguel y García Alén, Alfredo, "La necrópolis galaico-romana de La Lanzada (Noalla, Pontevedra) II". Cuadernos de Estudios Gallegos, 22 (1967), págs. 5-23.

Blanco Freijeiro, Antonio, Fusté Ara, Miguel y García Alén, Alfredo, "La necrópolis galaico-romana de La Lanzada (Noalla, Pontevedra). II. Conclusiones », Cuadernos de Estudios Gallegos, 22 (1967), págs. 129-155.

Bouet, Alain, Les matériaux de construction en terre cuite dans les thermes de la Gaule Narbonnaise, Talence, Ausonius, 1999.

Bouzón, Avelino, "Los vestigios arqueológicos en Currás (Tomiño)", Faro de Vigo, Edición Baixo Miño-Louriña (25-10-1995), pág. 4.

Carlsson-Brandt, Erik y Fernández Abella, David, "Nuevo hallazgo anfórico romano en Tui (Pontevedra)", Gallaecia, 32 (2013), págs. 257-268.

Carreño Gascón, Covadonga, "Baños privados y termas públicas en el Lugo romano», en M. ${ }^{a} \mathrm{~J}$. Peréx Agorreta, y A. Bazzana (coords.), Espacio, Tiempo y Forma, Serie II, Ha Antigua, T. V. Casa de Velázquez, UNED, 1992, págs. 337-350.

Carro Otero, José, "Los Esqueletos bajo-romanos de San Vicente de "O Grove"”, Cuadernos de Estudios Gallegos 26, 79 (1971), págs. 129-153.

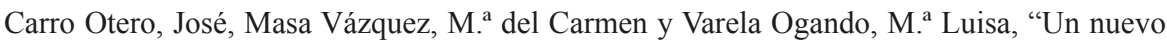
enterramiento de la necrópolis galaico-romana de la Lanzada (Noalla-Pontevedra)", Pontevedra Arqueológica II (1985-1986), págs. 229-252.

Carvalho, Helena Paula Abreu de, O povoamento romano na fachada ocidental do Conventus Bracarensis, tesis doctoral inédita, Universidade do Minho, 2008.

Chavarria Arnau, Alexandra, "El final de las villas y las transformaciones del territorio rural en el occidente (siglos V-VIII)”, en Carmen Fernández Ochoa, Virginia García Entero, 
Fernando Gil Sendino (eds.), Las «villae» tardorromanas en el occidente del Imperio: arquitectura y función, Coloquio Internacional de Arqueología en Gijón (4º 2006. Gijón), Gijón, Trea, 2008, págs. 193-214.

Currás Refojos, Brais X. y López González, Luis F. "Minería romana y poblamiento en la cuenca del Baixo Miño (Noroeste Peninsular)", en Carla María Braz Martins, Ana M. S. Bettencourt, José Inácio F. P. Martins y Jorge Carvalho (eds.), Povoamento e exploração dos recursos mineiros na Europa Atlántica Ocidental, Braga, CITCEM-APEQ, 2011, págs. 179-202.

Currás Refojos, Brais X., "Mapa de usos potenciales de la tierra de Galicia. Una perspectiva arqueológica", Trabajos de Prehistoria, 71, 1 (2014), págs. 23-41.

Currás Refojos, Brais X., Transformaciones sociales y territoriales en el Baixo Miño entre la Edad del Hierro y la integración en el Imperio Romano, tesis doctoral inédita, Universidad de Santiago de Compostela, 2014.

David, Pierre, Études historiques sur la Galice et le Portugal du VIe au XIIe siècle, Lisboa, Institut Français au Portugal, 1947.

Díaz Martínez, Pablo C., El reino suevo (411-585), Madrid, Akal, 2011.

Fernández Fernández, Adolfo, O comercio tardoantigo no Noroeste Penínsular: unha análise da Gallaecia sueva e visigoda a través do rexistro arqueolóxico, Noia, Toxosoutos, 2013.

Fernández Fernández, Adolfo, Pérez Losada, Fermín y Vieito Covela, Santiago, “Cerámica fina de importación en Toralla (Vigo): abastecimiento y consumo en una villa costera atlántica tardorromana", en Carmen Fernández Ochoa, Virginia García-Entero y Fernando Gil Sendino (eds.), Las «villae» tardorromanas en el occidente del Imperio: arquitectura y función, Coloquio Internacional de Arqueología en Gijón (4. 2006. Gijón), Gijón, Trea, 2008, págs. 575-586.

Fernández Castro, María Cruz, Villas romanas en España, Madrid, Dirección General de Bellas Artes, Archivos y Bibliotecas, 1982.

Fernández Ochoa, Carmen, Salido, Javier y Zarzalejos, Mar, "Las formas de ocupación rural en Hispania. Entre la terminología y la praxis arqueológica”, CuaPUAM, 40, (2014), págs. 111-136.

Fernández Rodríguez, Manuel, "Una necrópolis de tipo romano en Currás (Pontevedra)", en Homenaje al profesor Cayetano de Mergelina, Murcia, Universidad de Murcia, 1962, págs. 329-331.

Ferreira Priegue, Elisa, Los caminos medievales de Galicia. Boletín auriense, anexo 9, Ourense, Museo Arqueolóxico Provincial, 1988.

García Martínez, Manuel Carlos y Vázquez Varela, José Manuel, "La Necrópolis de "Adro Vello" (San Vicente de O Grove)”, Compostellanum 13, 4 (1968), págs. 563-571.

Gómez Sobrino, Jesús, González Santiso, Aquilino y Martínez do Tamuxe, Xoán "La villa romana y necrópolis germánica de Currás-Tomiño", Boletín del Museo Diocesano de Tui, 3 (1980), págs. 321-338.

González Fernández, X. Miguel, “Las tumbas romanas de Galicia”, Pontevedra Arqueológica II (1985-1986), págs. 209-228.

González Soutelo, Silvia y Cendón Fernández, Marta (eds.), Tui, presente, pasado y futuro: I Coloquio de Historia de Tui, Tui, 2006. 
González Soutelo, Silvia, O Tui antigo: unha aproximación histórica-arqueolóxica, Noia, Toxosoutos, 2007.

González Soutelo, Silvia, El valor del agua en el mundo antiguo: sistemas hidráulicos y aguas mineromedicinales en el contexto de la Galicia romana, A Coruña, Fundación Barrié, 2011.

González Soutelo, Silvia, Pérez Losada, Fermín, Valle Abad, Patricia y Vázquez Mato, Martín Xosé, "40 anos dun descubrimento. Crónica da investigación arqueolóxica sobre o xacemento romano e altomedieval de Currás, Tomiño (1972-2013)", Castellum Tyde. Revista do Instituto de Estudios Tudenses, 4 (2013-2014), págs. 33-58.

Iglesias Almeida, Ernesto y Méndez Cruces, Plácido, Evocación histórica de la ciudad de Tui y sus antiguas rúas, Tui, 1997.

Llinares García, Mar, Os Mouros no imaxinario popular galego, Santiago de Compostela, Universidade, Servicio de Publicacións, 1990.

López Quiroga, Jorge, "Después del "final" de las villae entre el Miño y el Duero (ss. VII-X): comunidades "fructuosianas", hábitat rupestre y "aldeas"”, CuPAUAM, 31-32 (2005-2006), págs. 219-245.

López-Costas, Olalla y Varela López, Tito, "Estudio craneométrico comparativo de los esqueletos de la necrópolis romana de A Lanzada, Noalla, Pontevedra", Museo de Pontevedra, 62 (2008), págs. 29-48.

Martínez de Tamuxe, Xoán M., La Vía romana «Per loca maritima» por el bajo Miño y costa atlántica, A Guarda, Imprenta Guardesa, 1975.

Martínez de Tamuxe, Xoán M., Citania y museo arqueológico de Santa Tecla, A Guarda, Patronato Municipal del Monte Santa Tecla, 1998.

Martínez Melón, José Ignacio, "El vocabulario de los asentamientos rurales (siglo I-IX d. C.): Evolución de la terminología", en Alexandra Chavarría, Javier Arce y Giorgo Brogiolo (eds.), Villas Tardoantiguas en el Mediterráneo Occidental, Anejos de Archivo Español de Arqueología, 39 (2006), págs. 113-32.

Naveiro López, Juan Luis, El Comercio antiguo en el N.W. peninsular: lectura histórica del registro arqueológico, Brigantium, 5, A Coruña, Museo Arqueolóxico Castelo de S. Antón, 1991.

Pérez Losada, Fermín, "Sobre o concepto de "villa" no mundo romano", Cadernos de arqueologia, serie II, 4 (1987), págs. 79-108.

Pérez Losada, Fermín, "Hipocaustos na Galicia romana”, Gallaecia, 13 (1992), págs. 129-175.

Pérez Losada, Fermín, "Hacia una definición de los asentamientos rurales en la Gallaecia: poblados (vici) y casas de campo (villae)", en Carmen Fernández Ochoa (ed.), Los finisterres atlánticos en la antigüedad: época prerromana y romana, Gijón, Electa, 1996, págs. 189-97.

Pérez Losada, Fermín, "Entre a Cidade e a Aldea: estudio arqueohistórico dos "aglomerados secundarios" romanos en Galicia”, Brigantium, 13 (2002), págs. 15-348.

Pérez Losada, Fermín, Vieito Covela, Santiago y Fernández Fernández, Adolfo, "Toralla y las villas marítimas de la Gallaecia atlántica: emplazamiento, arquitectura y función”, en Carmen Fernández Ochoa, Virginia García-Entero, Fernando Gil Sendino (eds.), Las «villae» tardorromanas en el occidente del Imperio: arquitectura y función, Coloquio Internacional de Arqueología en Gijón (4º . 2006. Gijón), Gijón, Trea, 2008, págs. 481-506. 
Pérez Losada, Fermín y González Soutelo, Silvia (eds.), Tomiño romano: o xacemento de Currás: ano 2014 [exposición], Tomiño, Concello de Tomiño, 2014.

Rodríguez Colmenero, Antonio, Ferrer Sierra, Santiago y Álvarez Asorey, Rubén D., Miliarios e outras inscricións viarias romanas do noroeste hispánico: (conventos bracarense, lucense e asturicense), Lugo, Consello da Cultura Galega, Sección de Patrimonio Histórico, 2004.

Rodríguez Martínez, Rafael M., "Re-excavando Santa Trega (A Guarda, Pontevedra). Nuevos datos y conclusiones del Barrio Mergelina", Férvedes, 9 (2018), págs. 107-116.

Rodríguez Martínez, Rafael M., "O sitio arqueolóxico da Lanzada a través dos seus materiais", en Sanxenxo na historia. Volume IV: Arte, patrimonio e mundo rural, IV: Arte, patrimonio e mundo rural, Santiago de Compostela, Galicia Milenio, 2015, págs. 269-286.

Rodríguez Martínez, Rafael M., Aboal Fernández, Roberto, Castro Hierro, Virginia, Cancela Cereijo, Cristina y Rodríguez Paz, Anxo, Intervención arqueolóxica para a recuperación patrimonial do xacemento de A Lanzada, Informe valorativo, Pontevedra, 2010.

Rodríguez Resino, Álvaro, Del Imperio Romano a la Alta Edad Media: arqueología de la Tardoantigüedad en Galicia (siglos V-VIII), Noia, Toxosoutos, 2006.

Romero Masiá, Ana María, Pose Mesura, Xosé Manuel, Galicia nos textos clásicos, A Coruña, Museo Arqueolóxico Provincial, 1987 (Monografías Urxentes do Museu, 3).

Valle Abad, Patricia, Pérez Losada, Fermín, González Soutelo, Silvia y Vázquez Mato, Martín Xosé, "El yacimiento romano-medieval de Os Medos (Currás, Tomiño). Aproximación a la explotación de un territorio fluvial (Baixo Miño) entre la Antigüedad y la Edad Media", en L. Castro, B. Comendador, E. de Uña, F. Pérez, S. Reboreda (eds.), Paisajes culturales del Agua (arqueología, antigüedad y territorio), Ourense, Diputación de Ourense, 2016, págs. 127-136.

Vieito Covela, Santiago, Pérez Losada, Fermín y Fernández Fernández, Adolfo, "El material cerámico de construcción de la "villa" y necrópolis de Toralla: tipología y usos", en Carmen Fernández Ochoa, Virginia García-Entero y Fernando Gil Sendino (eds.), Las «villae» tardorromanas en el occidente del Imperio: arquitectura y función, Coloquio Internacional de Arqueología en Gijón (4². 2006. Gijón), Gijón, Trea, 2008, págs. 755-766. 